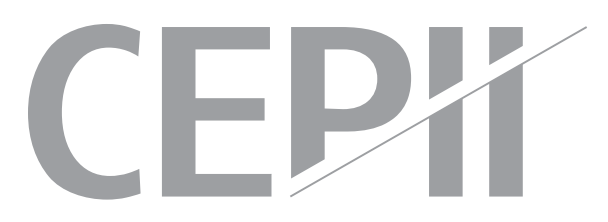

\title{
The Cost of Non-Europe, Revisited
}

Thierry Mayer, Vincent Vicard \& Soledad Zignago

\section{Highlights}

- We estimate the trade-related welfare gains from the European Union.

- Strong estimated trade effect of the EU - rising over time - based on structural gravity.

- The Single Market increases bilateral trade more than three times as much as a "normal" RTA.

- The costs of Non-Europe (weighted by country size) are estimated to vary between $3 \%$ and $7 \%$ on average for the EU depending on the counterfactual ("normal" RTA vs return to WTO rules notably).

- Wide variation across member countries: small open economies in Europe gain the most, particularly the Eastern part of the continent.

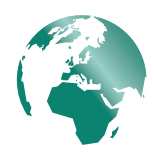




\section{Abstract}

In this paper we quantify the "Cost of Non-Europe", i.e. the trade-related welfare gains each country member has reaped from the European Union. Thirty years after the terminology of Non-Europe was used to give estimates of the gains from further integration, we use modern versions of the gravity model to estimate the trade creation implied by the EU, and apply those to counterfactual exercises where for instance the EU returns to a "normal", shallow-type regional agreement, or reverts to WTO rules. Those scenarios are envisioned with or without the exit of the United Kingdom from the EU (Brexit) happening, which points to interesting cross-country differences and potential cascade effects in doing and undoing of trade agreements.

\section{Keywords}

Trade Integration, Gravity, European Union.

\section{DEL}

F1.

\section{Working Paper}

\section{CEPI}

CEPII (Centre d'Etudes Prospectives et d'Informations Internationales) is a French institute dedicated to producing independent, policyoriented economic research helpful to understand the international economic environment and challenges in the areas of trade policy, competitiveness, macroeconomics, international finance and growth.
CEPII Working Paper

Contributing to research in international economics

C C CEPII, PARIS, 2018

All rights reserved. Opinions expressed in this publication are those of the author(s) alone.

$\begin{array}{ll}\text { Editorial Director: } & \text { CEPII } \\ \text { Sébastien Jean } & \text { 20, avenue de Ségur } \\ & \text { TSA 10726 } \\ \text { Production: } & 75334 \text { Paris Cedex } 07 \\ \text { Laure Boivin } & +33153685500 \\ & \text { www.cepii.fr } \\ \text { No ISSN: } 1293-2574 & \text { Press contact: presse@ }\end{array}$


The Cost of Non-Europe, Revisited ${ }^{1}$

Thierry Mayer*, Vincent Vicard ${ }^{\dagger}$ and Soledad Zignago ${ }^{\ddagger}$

\section{Introduction}

Sixty years after the Treaty of Rome came into force, and a quarter century after the implementation of the Single Market Program (SMP, started in 1987 and achieved in 1993), we live in an age where a possible scenario for the near future is one of trade disintegration in Europe, reversing what is probably the deepest and most prolonged trade liberalization processes in modern history. The choice of the United Kingdom to exit the EU (Brexit) combines with the calls from many governments (even ones seen as moderate) for a reversal of key integration agreements like Schengen, to give a bleak picture of what comes next. This makes it a good time to revisit the gains the EU has reaped from trade integration since 1958 and what would be the costs of going backwards. ${ }^{2}$

On the academic front is a happy coincidence that the techniques available to estimate those gains and costs have come to maturity recently, enabling a relatively easy quantification of different scenarios which might characterize the near future of the continent. In particular, the work by Dekle et al. (2007), Arkolakis et al. (2012), and following papers summarized in Costinot and Rodriguez-Clare (2014), has shown that the most popular models that trade economists have been developing and using since the late 1970s (a large class of models featuring important diversity in assumptions regarding demand systems and market structure) have two very convenient properties for the purpose of quantifying Gains From Trade (GFT):

\footnotetext{
${ }^{1}$ We thank participants of the DG Trade Chief Economist seminar and CompNet conference (Brussels, June 2017), CEPII seminar (Paris, July 2017), and Banque de France seminar (Paris, September 2017) for very useful discussions and comments. The opinions expressed in this paper are those of the authors and do not reflect the views of the Banque de France. This research has received funding from the European Research Council (ERC) under the Grant Agreement No. 313522.

*Sciences-Po, Banque de France, CEPII and CEPR, (thierry.mayer@sciencespo.fr)

${ }^{\dagger}$ CEPII, (vincent.vicard@cepii.fr)

¥Banque de France, (soledad.zignago@banque-france.fr)

${ }^{2}$ In the following, we consider trade agreement creation and disintegration as symmetric and use alternatively the terms gains from EU integration and costs of exit. Hysteresis effects related to past trade integration may however generate asymmetries.
} 
i) trade frictions are estimable in a simple way using the "structural" version of the gravity equation; ii) endowed with those frictions, it is easy to run counterfactuals using an approach often referred to as Exact Hat Algebra (EHA) that imposes minimal data requirement.

This paper can be seen as a re-assessment of the "Cost of non-Europe". The very first assessment was the one carried out in 1988, in an official European Commission report estimating the likely gains that would come from the achievement of the Single Market Programme by the end of 1992 (Checchini et al., 1988). The initial report was an ambitious ex-ante exercise, aimed at identifying the gains from removing various types of non-tariff barriers (NTBs) that were seen as a major impediment in the full achievement of the initial goals of the Treaty of Rome. At the same period, a large number of partial or general equilibrium exercises-summarized in detail by Baldwin and Venables (1995)-have been conducted to quantify the gains to be expected from "EC92". The European Commission also commissioned in 1996 an early ex-post evaluation of the benefits of the Single Market; in particular, Fontagné et al. (1998) focus on the nature of intra-EU trade flows and emphasizes adjustments within industries on the quality spectrum. Our paper is an ex-post exercise quantifying what would be the costs of un-doing what has been achieved over all those years in terms of European integration. We propose various scenarios of EU disintegration, ranging from the return to a "standard" free trade agreement to the return to WTO rules under which each former EU country would apply the current MFN (Most Favoured Nation) tariffs to its former EU partners. Our work is related is related to numerous recent quantifications of trade policy scenarios, and in particular to Costinot and Rodriguez-Clare (2014) and Dhingra et al. (2016). The latter paper provides a quantification of the trade effects of Brexit, using a framework very similar to ours. Compared to this paper, our work takes a broader perspective and evaluates various scenarios of overall EU disintegration, taking into account Brexit. Another contribution is that we ground our simulations with our own estimates of the direct trade effects of the EU using the latest available data and techniques of structural gravity estimation.

Our results show that the EU provides for deep trade integration over and above tariffs cuts: we find a (partial) trade impact of the Single Market more than three times larger than a regular RTA. In our preferred simulation, the Single market is found to have increased trade between EU members by $109 \%$ on average for goods and $58 \%$ for tradable services. The associated welfare gains from EU trade integration are estimated to reach $4.4 \%$ for the average European country (weighted by the size of the economy). Not all countries have benefited to the same extent however. In order to graphically illustrate the distribution of those gains, Figure 1 
shows two maps. The map on the left of the figure shows trade increases and the one on the right shows welfare changes for each of the EU28 countries. Welfare gains from EU integration are significantly larger for small open economies than for large EU members. It is also very striking that Eastern European countries have been major benefiters of the integration process.

Figure 1 - The effect of European integration on trade and welfare
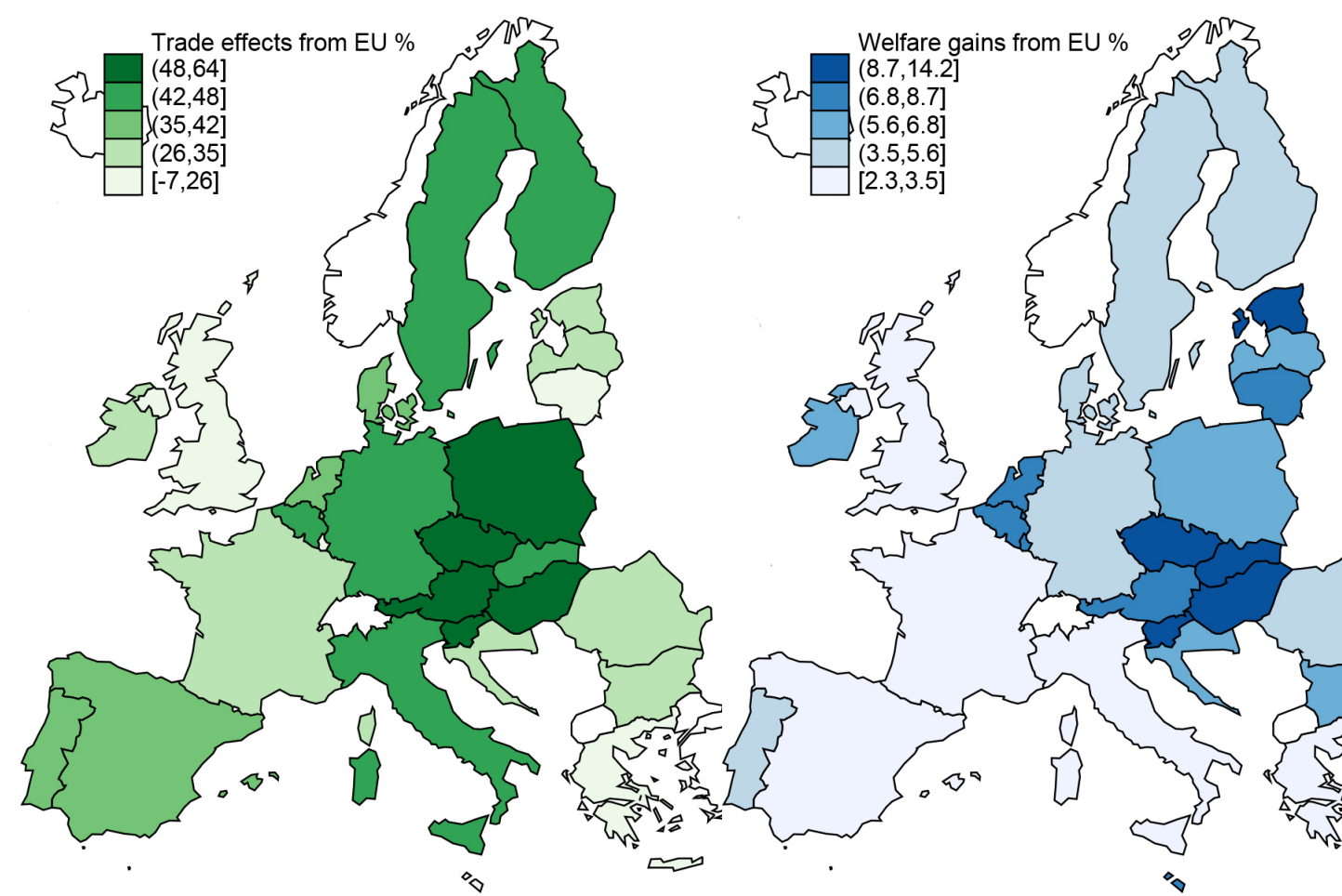

The left panel presents the percentage increase in total trade in goods due to EU membership from column (1) in Table 7. The right panel shows welfare changes from Table 8 (column (1)). Both panel report results from the RTA scenario including intermediate inputs.

Another of our results that parallels with a frequent finding in the literature, is that estimation methods matter. PPML yield smaller (although still substantial and very significant) estimates of the trade gains associated with the EU than OLS. Interestingly, depending on how one interprets those lower estimated coefficient on EU using PPML - as differences in trade elasticities or differences in ad valorem equivalent of trade costs - the gains from EU integration can be magnified or dampened compared to the standard OLS case.

Several qualifications are in order regarding the scope of our analysis. We estimate the economic gains from European integration through the trade channel. We are therefore silent about other dimensions of European integration, such as the free 
mobility of capital and labor or the monetary union, or non-economic gains. ${ }^{3}$ Also, by the supranational nature of the EU, member countries may benefit from a more efficient provision of public goods (e.g. external trade policy, competition policy, monetary policy...) as well as incur costs related to the heterogeneity of preferences between members (Spolaore et al., 2000, being a classical reference on the topic).

In addition, our framework does not feature dynamic gains. From a theoretical point of view, dynamic gains from trade are ambiguous: improved market access may induce more innovation but increased competition may induce some of this innovation to be defensive, i.e. to dampen the pro-competitive gains from trade. Increased competition might also reduce the rents from innovation (Aghion and Howitt, 1992; Aghion et al., 1997). From an empirical point of view, Bloom et al. (2016) find a positive impact of trade liberalization (the increase of Chinese competition in their case) on innovation activities for a panel of European firms. Autor et al. (2016) find a contrasting negative impact on US firms. Taking a stance on this topic would involve a detailed empirical analysis of those dynamic gains nested within the structural gravity framework. Developing a fully dynamic model of structural gravity with endogenous innovation in general equilibrium goes beyond the scope of this paper. We therefore concentrate on static gains.

There are two main steps in our analysis. The first one produces estimates of EU integration effects on trade through gravity estimation. In those regressions, we separate the EU agreements from the rest of regional trade deals, and estimate the surplus of trade flows that is due to various sides of the EU process (the single market, Schengen, and the euro notably). This provides us with a set of parameters driving the direct trade effects of the EU. Those can be first compared to the literature, and then used in the second step, i.e. the Exact Hat Algebra counterfactual simulations. The first step is conducted in section 2; the methodology of the second is presented in section 3 and the results in section 4 . Section 5 investigates how Brexit affects gains from EU integration of remaining members. The last section concludes.

\section{Estimating the impact of RTAs}

\subsection{Structural Gravity}

The first step towards welfare evaluation of changes in trade policies relies on the gravity model, which describes how bilateral imports of country $n$ from country $i$ in

\footnotetext{
${ }^{3}$ Political stability being probably the most important of those non-economic gains. Martin et al. (2012) and Vicard (2012) emphasize the security gains associated with regional trade integration.
} 
period $t$ react to changes in the level of bilateral "freeness" of trade, denoted $\phi_{\text {nit }}$. The gravity model has been used at least since the 1960s. Tinbergen (1962), often cited as the first application of gravity to trade flows, was actually an evaluation of the trade effects of preferential trading relationships (namely the British Commonwealth and the Belgium-Netherlands-Luxembourg customs union soon to be subsumed in the European Community). The modern version of gravity, motivated by evaluation of policy-relevant counterfactuals, requires theoretical foundations. A surprisingly large set of models (covered in Head and Mayer (2014), and referred to as structural gravity) explain trade flows as

$$
X_{n i t}=\underbrace{\frac{Y_{i t}}{\Omega_{i t}}}_{S_{i t}} \underbrace{\frac{X_{n t}}{\Phi_{n t}}}_{M_{n t}} \phi_{n i t}
$$

where $Y_{i t}=\sum_{n} X_{n i t}$ is the value of production, $X_{n t}=\sum_{i} X_{n i t}$ is the value of the importer's expenditure on all source countries, and $\Omega_{i t}$ and $\Phi_{n t}$ are "multilateral resistance" (MR) terms defined as

$$
\Phi_{n t}=\sum_{\ell} \frac{\phi_{n \ell t} Y_{\ell t}}{\Omega_{\ell t}} \quad \text { and } \quad \Omega_{i t}=\sum_{\ell} \frac{\phi_{\ell i t} X_{\ell t}}{\Phi_{\ell t}}
$$

The $\Phi_{n}$ term represents competition between different sources that importing country $n$ is faced with. The theoretical foundations of gravity have $\Phi_{n}$ closely related to the price index of country $n$. A higher $\Phi_{n}$ lowers the market share of country $\ell$ in $n$ by raising the relative price of buying from $\ell$. The $\Omega$ term comes from the market clearing condition that total sales from $i$ (including the domestic sales) have to sum up to output value.

An immediately apparent feature of structural gravity is its multiplicative form. After taking logs, this means that the effect of multilateral resistance terms can be captured by time-varying exporter and importer fixed effects:

$$
\ln X_{n i t}=\ln S_{i t}+\ln M_{n t}+\ln \phi_{n i t} .
$$

Another key feature is that the level of trade flows between $n$ and $i$ is affected by third countries, only through the $\Phi$ and $\Omega$ terms that are specific to the exporter and importer respectively. This points to a renewed interpretation of the trade creation and trade diversion concepts as direct effects and indirect effects, through multilateral resistance terms, of changes in policy variables included in $\phi_{\text {nit }}$. An increase in $\phi_{\text {nit }}$ is directly increasing bilateral trade flows between $n$ and $i$, while also changing the relative trade costs (and delivered price under the usual assumptions on pass-through) through its impact on MR terms. Consumers therefore reallocate 
demand according to new relative prices, diverting trade coming from all nonmembers in the case of RTA signature. When estimating the gravity equation, the origin (-time) and destination (-time) fixed effects neutralize those reallocation effects, such that the coefficients estimated on the RTA dummy are the "pure" trade creation effects. In the counterfactual scenarios, the structure of the model is used to solve for the indirect effects of $\phi_{\text {nit }}$ that go through MR terms in (2).

\subsection{Endogeneity of RTAs and zeroes}

Apart from the use of fixed effects for origin and destinations, there are two main remaining issues with estimation of equation (3). The first relates to potential endogeneity of the main variables of interest, i.e. different RTAs. It is very likely that pairs sharing a regional agreement might also be characterized by other unobserved bilateral proximity factors. This is a concern that has been considered in the literature, examples including Carrere (2006), Baier and Bergstrand (2007) or more recently Bergstrand et al. (2015) and Limão (2016). The most common treatment of that issue is to include bilateral fixed effects to the regression:

$$
\ln X_{n i t}=\mathrm{FE}_{i t}+\mathrm{FE}_{n t}+\mathrm{FE}_{n i}+\ln \phi_{n i t}
$$

Because of the very large size of datasets in gravity equations (combined with improved estimation techniques), this high-dimensional fixed effects approach is a feasible one, that identifies variables in the pure within dimension. For instance, we might be concerned that Canada and the United States are in a RTA because of their continued good political relationship over the last century (at least), and that this might affect directly trade flows, biasing the estimated coefficient on CUSA/NAFTA. The bilateral fixed effect is treating this concern, which is now passed to the within dimension: we have to worry about the timing of CUSA/NAFTA. Maybe it is because the alignment of those two countries' diplomatic interests was especially high during the end of the 1980s that those agreements were signed. At this point, there is little else to do than to add a credible set of bilateral-time controls.

Another issue is that even at the aggregate level of total trade in the recent period, there are combinations of country-pairs that do not trade. Those zeroes are again obviously not random, and might introduce selection bias, as first emphasized by Helpman et al. (2008). There are several approaches to deal with this type of selection bias. One is the PPML approach emphasized by Santos Silva and Tenreyro (2006), an alternative is the generalized tobit introduced by Eaton and Kortum (2001). Unfortunately i) none of them is ideal since the performance of 
each method depends on assumptions on the process generating the zeroes, and on the type of error term (for an indepth survey analysis of the potential biases, see Head and Mayer (2014)), ii) both methods present computational challenges when the dataset gets large. Since those computational issues have received more attention for PPML than for generalized Tobit, we present PPML results as a set of alternative estimates that can handle zeroes (on top of dealing with the type of heteroskedasticity that Santos Silva and Tenreyro (2006) originally advocated PPML for).

\subsection{Results}

Estimation of equation (3) is carried out in two parts, the first-covering goods-uses a large scale bilateral dataset that covers all country pairs from 1950 to 2012. This dataset is an extension of Head et al. (2010) to recent years. It is primarily based on IMF DOTS trade flows data combined with CEPII gravity datasets, updated notably on the relevant policy variables. As pointed out in Limão (2016), estimates of RTA effects might suffer from small sample bias, since those are identified on a few observations inside a country pair. This is our main motivation for using this long-run panel for trade in goods, the downside being its lack of sectoral detail. We also use a (shorter) panel of bilateral flows in commercial services, which is an extended version of the data used in Head et al. (2009). The primary source for this type of trade is Eurostat, which provides the best available data to our knowledge for trade in services. We feel that accounting for trade in services is quite important since there are many aspects of the EU integration process that concern trade in services directly (free trade in services was an objective from the very start of the process) or indirectly (notably through the free mobility of people and capital, since trade in services often requires movement of labor and/or local investment).

\subsubsection{Trade in goods and the EU}

Column (1) in Table 1 presents results of a naive gravity estimation, that replaces the theoretically-consistent country-year effects in equation (3) with size proxies accounting for population and income per capita. The naive approach also features the usual time invariant bilateral variables such as distance or common language in place of the bilateral fixed effect. The findings are in line with the rest of the literature, where size effects exhibit elasticities near 1 , and distance reduces trade with an elasticity close to -1 . The usually included set of proximity variables all promote trade, colonial linkages, contiguity and common language being the most substantial trade-promoters. 
Table 1 - Gravity results of European integration in goods

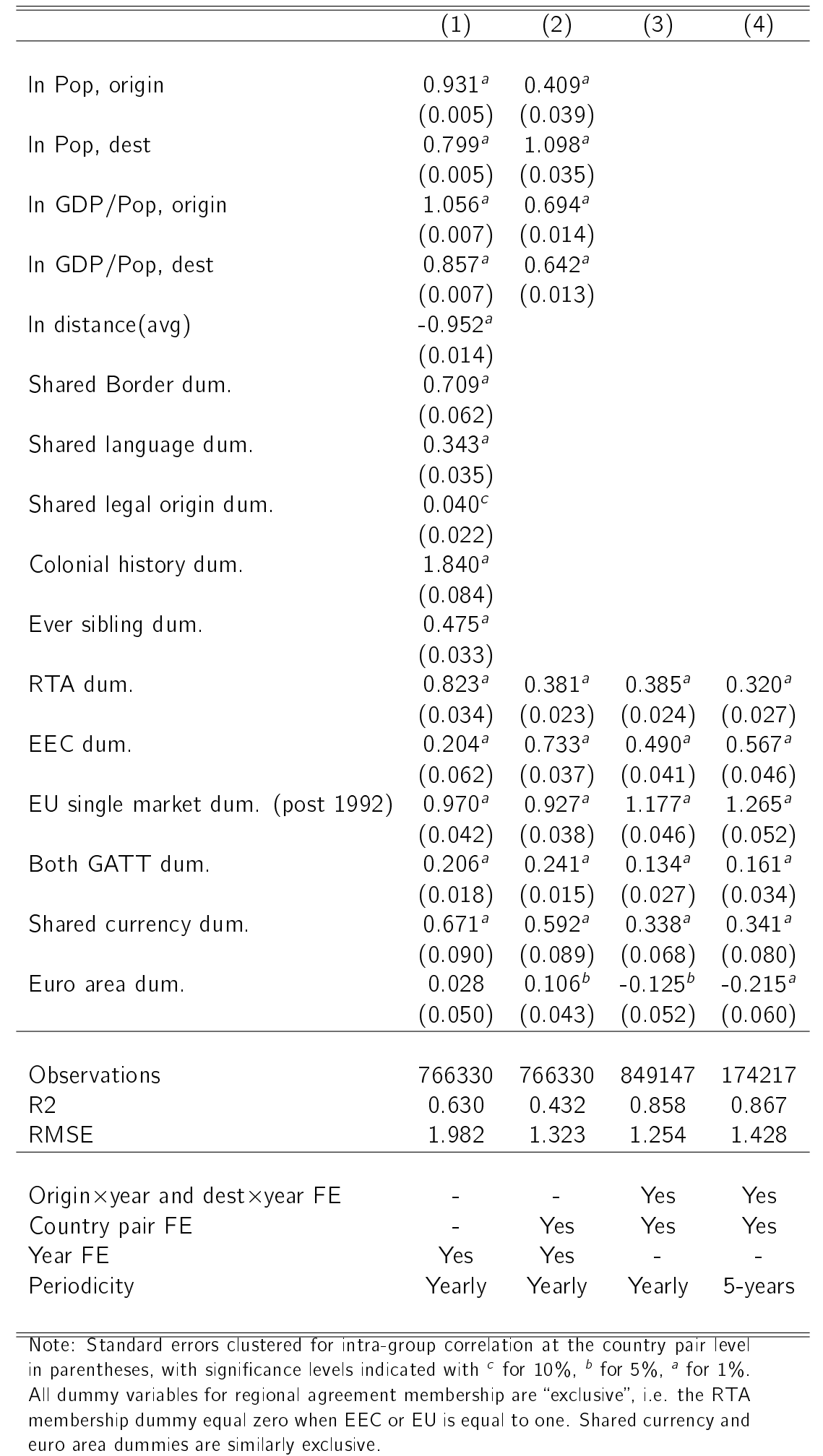


The variables of interest for our purpose start with RTA, which is estimated to strongly promote trade. The direct (partial) impact of having an RTA active between two countries is to more than double trade flows. Such naive gravity however yields low estimates for the EC/EU, implying a much smaller trade increase before 1992 and similar to the average RTA after the implementation of the single market. Note that we define all membership variables in an exclusive manner, i.e. RTA is set to zero when EC or EU equals one (the same applies to the shared currency and the euro area dummies). GATT/WTO has a positive estimated effect, substantial but markedly smaller than the effect of regional agreements. Finally, sharing a currency has the usual positive and large effect. We add a dummy variable for the euro, which does not seem to significantly promote trade.

Column (2) starts to introduce fixed effects, accounting for bilateral heterogeneity in trade patterns. The set of time-invariant bilateral variables like distance are dropped and the set of variables of interest in the bottom of the table is now estimated in the within dimension. The effect of standard RTAs drop as expected. RTAs are likely to be associated with omitted positive drivers of trade that are captured by the bilateral fixed effects. It however remains positive and very significant: bilateral trade is estimated to be around $40 \%$ larger after the signature of a regional agreement. The EU is estimated to be an even larger trade creator unlike in the first column. Note that the EU is a particular case in several dimensions. The depth of the agreement is the first dimension. The effect of depth of the agreement is perhaps most visible in the post 92 effect, estimated to more than double trade $(\exp (0.927)=2.52)$. The second dimension is that the EU experienced several enlargements over time (in 1973, 1981, 1986, 1995, 2004, 2007 and 2013). Each of those helps identification of the trade creating effects of the two EU variables in the within dimension. GATT/WTO, shared currency and the eurozone dummies all keep the same sign with the use of bilateral fixed effects. It is interesting to note that the within estimate of the euro is larger and more statistically significant than the naive coefficient from column (1) that comes mostly from the cross-sectional dimension.

Column (3) is the theory-consistent estimate of the gravity equation in goods, which adds importer-time and exporter-time fixed effects, capturing the multilateral resistance terms. The qualitative pattern of our variables of interest is unchanged for the most part, one exception being the trade impact of the euro. The introduction of country-year effects reverses its sign. Note that the coefficient on shared currency is also substantially decreased. Our results confirm the literature finding (Baldwin, 2006, for instance) that a common currency, and the euro in particular, have a trade effect that is very sensitive to the set of fixed effects introduced in 
the regression.

Our preferred estimate of the EU effects are in column (3), and state that the single market version of the EU triples trade $(\exp (1.177)=3.24)$. A very comparable recent estimate is the one from Limão (2016), who distinguishes between "standard" free trade agreements and a dummy variable for customs unions/common market/economic union. The benchmark estimate reported for this type of agreements, using structural gravity, is 1.16 , strikingly close to our results, while he reports a coefficient of 0.533 for "normal" free trade areas. The preferred EU effects estimate of Baier et al. (2014) and Eicher and Henn (2011) are other examples finding that the deep integration agreements such as the EU have a much larger trade impact than standard RTAs. A number of older papers (Carrere (2006), Baier et al. (2008)) have found converging estimates around . 6 to .7 for the EU.

We can use our results to show that the impact of RTAs on trade goes well beyond the fall in tariffs implied by the agreement. In the case of a deep agreements such as the EU, the reduction of non-tariffs barriers and other behind-the-border trade costs are even more prevalent and should add a lot to the simple cut in tariffs. World Trade Organization (2011) reports an average preferential margin of 4.9 percentage points for trade within the EU compared to its MFN tariffs. Our preferred EU effect would involve an elasticity of trade of $1.177 / \ln (1.049)=24.6$, if accounted by tariff cuts only. This is well beyond the median estimate of 5.03 found in the meta analysis of Head and Mayer (2014), which summarizes the typical findings of that literature. Put another way, the direct (partial) trade impact of tariffs cut alone under the EU would be to multiply bilateral trade between members by a factor of $\exp (0.049)^{5.03}=1.28$, to be compared with the overall EU effect around 3 that we estimate. Note that the trade impact implied by the preference margin is close to the estimated effect of an average RTA $(\exp (0.385)=1.47)$, as in the meta-analysis of Head and Mayer (2014). This underlines the major role played by provisions on non-tariffs barriers in deep RTAs such as the EU, as emphasized by Limão (2016).

The last column of Table 1 follows an approach frequent in the literature that consists in averaging the data over periods of 5 years (Cheng and Wall, 2005). This tends to mitigate measurement error in the annual trade flows reported which can be quite large even at this level of aggregation. The changes in coefficients are marginal. 
Table 2 - Different dimensions of EU integration for trade in goods

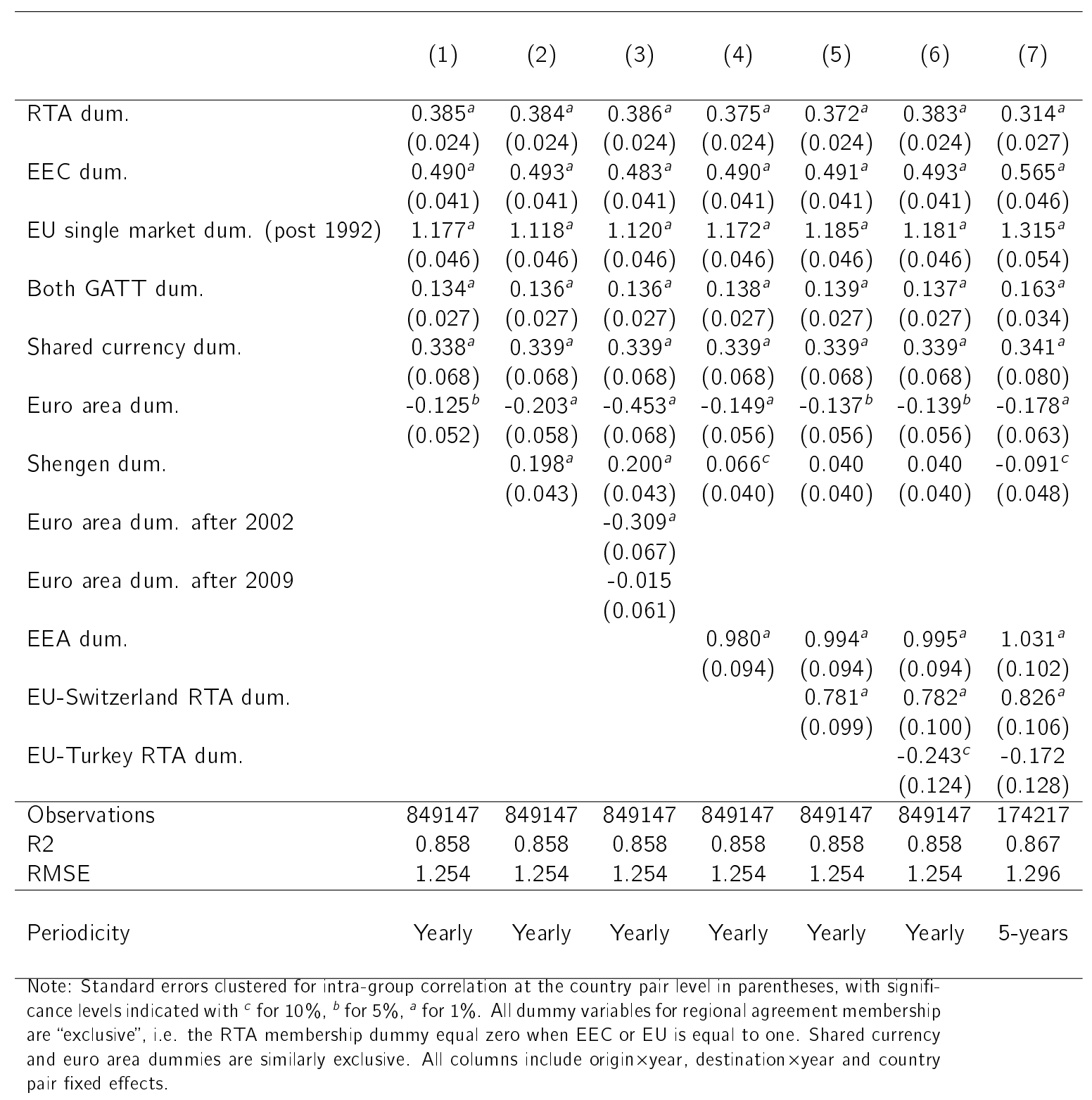


Table 3 - Date of entry into force of various European integration agreements (1948-2012)

\begin{tabular}{|c|c|c|c|c|c|c|c|}
\hline & EEC & $\begin{array}{c}\text { EU } \\
\text { (single market) }\end{array}$ & Schengen & Euro area & EEA & $\begin{array}{c}\text { EU- } \\
\text { Switzerland }\end{array}$ & $\begin{array}{c}\text { EU- } \\
\text { Turkey }\end{array}$ \\
\hline Austria & - & 1995 & 1997 & 1999 & 1994 & 2002 & 1996 \\
\hline Belgium & 1958 & 1993 & 1995 & 1999 & 1994 & 2002 & 1996 \\
\hline Bulgaria & - & 2007 & - & - & 2007 & 2007 & 2007 \\
\hline Cyprus & - & 2004 & - & 2008 & 2004 & 2004 & 2004 \\
\hline Czech Republic & - & 2004 & 2008 & - & 2004 & 2004 & 2004 \\
\hline Denmark & 1973 & 1993 & 2001 & - & 1994 & 2002 & 1996 \\
\hline Estonia & - & 2004 & 2008 & 2011 & 2004 & 2004 & 2004 \\
\hline Finland & - & 1995 & 2001 & 1999 & 1994 & 2002 & 1996 \\
\hline France & 1958 & 1993 & 1995 & 1999 & 1994 & 2002 & 1996 \\
\hline Germany & 1958 & 1993 & 1995 & 1999 & 1994 & 2002 & 1996 \\
\hline Greece & 1981 & 1993 & 2000 & 2001 & 1994 & 2002 & 1996 \\
\hline Hungary & - & 2004 & 2008 & - & 2004 & 2004 & 2004 \\
\hline Ireland & 1973 & 1993 & - & 1999 & 1994 & 2002 & 1996 \\
\hline Italy & 1958 & 1993 & 1997 & 1999 & 1994 & 2002 & 1996 \\
\hline Latvia & - & 2004 & 2008 & 2014 & 2004 & 2004 & 2004 \\
\hline Lithuania & - & 2004 & 2008 & 2015 & 2004 & 2004 & 2004 \\
\hline Luxembourg & 1958 & 1993 & 1995 & 1999 & 1994 & 2002 & 1996 \\
\hline Malta & - & 2004 & 2008 & 2008 & 2004 & 2004 & 2004 \\
\hline Netherlands & 1958 & 1993 & 1995 & 1999 & 1994 & 2002 & 1996 \\
\hline Poland & - & 2004 & 2008 & - & 2004 & 2004 & 2004 \\
\hline Portugal & 1986 & 1993 & 1995 & 1999 & 1994 & 2002 & 1996 \\
\hline Romania & - & 2007 & - & - & 2007 & 2007 & 2007 \\
\hline Slovakia & - & 2004 & 2008 & 2009 & 2004 & 2004 & 2004 \\
\hline Slovenia & - & 2004 & 2008 & 2007 & 2004 & 2004 & 2004 \\
\hline Spain & 1986 & 1993 & 1995 & 1999 & 1994 & 2002 & 1996 \\
\hline Sweden & - & 1995 & 2001 & - & 1994 & 2002 & 1996 \\
\hline United Kingdom & 1973 & 1993 & - & - & 1994 & 2002 & 1996 \\
\hline Iceland & - & - & 2001 & - & 1994 & - & - \\
\hline Norway & - & - & 2001 & - & 1994 & - & - \\
\hline Switzerland & - & - & 2009 & - & - & 2002 & - \\
\hline Turkey & - & - & - & - & - & - & 1996 \\
\hline
\end{tabular}




\subsubsection{Measuring different dimensions of European trade integration}

Table 2 details the different dimensions of trade creating effects of the EU. It starts by reproducing our preferred regression from Table 1 and then adds a number of controls in the following columns. The controls are describing the intricate network of European agreements that are likely to affect trade flows. In Table 3, we detail the dates of entry into force of those agreements and their different membership patterns.

The first of those controls is a dummy for Schengen agreement. This agreement, which involves mostly - but not exclusively - EU countries improves on the liberalization of international travel inside the zone, which essentially operates as a border-less entity. Free mobility of labor therefore seems to have a substantial effect on trade flows. In column (2) the introduction of Schengen makes the eurozone dummy more negative and significant. In order to dig into this intriguing finding, we separate in column (3) the effect of the euro between different subperiods. Results suggest that the negative effect of the euro on trade within the euro area is particularly strong during the first years of the euro implementation, and may capture business cycle fluctuations. By 2009, the coefficient on euro area membership is close to 0 and insignificant.

Column (4) investigates the effect of the European Economic Area, a free trade agreement between the EU and the remaining parts of EFTA. EFTA was itself a free trade agreement passed in 1960 among a group of European nations that were not part of the European Community. Most of its members have gradually entered the EC/EU, and in 1992, the EEA was signed to establish free trade (together with important rules concerning the adoption of EU legislation by EEA members) between EU and what remained of EFTA (today Iceland, Liechtenstein, Norway and Switzerland). Through membership to the EEA, Iceland, Liechtenstein and Norway are members of the Single market but do not form a customs union with the EU. Switzerland did not ratify the treaty, and its relations with the EU are governed by a number of bilateral treaties, which we consider with a dummy introduced in column (5). Both EEA and EU-Switzerland RTAs are important determinants of trade flows, coefficients being quite comparable to the EU-post 92 effect as should be expected from the nature of the agreements. Note that the slightly lower point estimate on the EEA, corresponding to the cost of customs formalities and/or of rules related to being a third party to the customs union, is not statistically different from the EU-post 92 coefficient. Last, we consider the EU-Turkey customs union entered into force in 1996, but the effects here are weak at best. 


\subsubsection{Heterogenous elasticities: OLS vs. PPML}

Table 4 - Gravity results of European integration in goods: alternative estimators

\begin{tabular}{|c|c|c|c|c|c|c|}
\hline $\begin{array}{l}\text { Estimator } \\
\text { Sample }\end{array}$ & $\begin{array}{l}(1) \\
\text { OLS }\end{array}$ & $\begin{array}{c}(2) \\
\text { PPML }\end{array}$ & $\begin{array}{c}(3) \\
\text { PPML } \\
\text { flow }>0\end{array}$ & $\begin{array}{c}\text { (4) } \\
\text { OLS } \\
\text { weighted }\end{array}$ & $\begin{array}{c}(5) \\
\text { PPML } \\
\text { share }\end{array}$ & $\begin{array}{c}(6) \\
\text { PPML } \\
\text { share } \\
\text { flow }>0\end{array}$ \\
\hline RTA dum. & $\begin{array}{c}0.383^{a} \\
(0.024)\end{array}$ & $\begin{array}{c}0.060 \\
(0.046)\end{array}$ & $\begin{array}{c}0.065 \\
(0.046)\end{array}$ & $\begin{array}{c}0.077^{c} \\
(0.042)\end{array}$ & $\begin{array}{c}0.168^{a} \\
(0.027)\end{array}$ & $\begin{array}{c}0.207^{a} \\
(0.025)\end{array}$ \\
\hline EEC dum. & $\begin{array}{c}0.493^{a} \\
(0.041)\end{array}$ & $\begin{array}{c}0.558^{a} \\
(0.059)\end{array}$ & $\begin{array}{c}0.566^{a} \\
(0.059)\end{array}$ & $\begin{array}{c}0.580^{a} \\
(0.055)\end{array}$ & $\begin{array}{c}0.634^{a} \\
(0.047)\end{array}$ & $\begin{array}{c}0.642^{a} \\
(0.046)\end{array}$ \\
\hline EU single market dum. (post 1992) & $\begin{array}{c}1.181^{a} \\
(0.046)\end{array}$ & $\begin{array}{c}0.650^{a} \\
(0.059)\end{array}$ & $\begin{array}{c}0.649^{a} \\
(0.058)\end{array}$ & $\begin{array}{c}0.624^{a} \\
(0.054)\end{array}$ & $\begin{array}{c}0.944^{a} \\
(0.067)\end{array}$ & $\begin{array}{c}0.915^{a} \\
(0.064)\end{array}$ \\
\hline Both GATT dum. & $\begin{array}{c}0.137^{a} \\
(0.027)\end{array}$ & $\begin{array}{c}-0.096 \\
(0.074)\end{array}$ & $\begin{array}{c}-0.063 \\
(0.075)\end{array}$ & $\begin{array}{c}0.084 \\
(0.065)\end{array}$ & $\begin{array}{c}0.042 \\
(0.041)\end{array}$ & $\begin{array}{c}0.106^{a} \\
(0.038)\end{array}$ \\
\hline Shared currency dum. & $\begin{array}{c}0.339^{a} \\
(0.068)\end{array}$ & $\begin{array}{c}0.816^{a} \\
(0.127)\end{array}$ & $\begin{array}{c}0.779^{a} \\
(0.125)\end{array}$ & $\begin{array}{c}0.536^{a} \\
(0.098)\end{array}$ & $\begin{array}{c}0.476^{a} \\
(0.060)\end{array}$ & $\begin{array}{c}0.454^{a} \\
(0.059)\end{array}$ \\
\hline Euro area dum. & $\begin{array}{c}-0.139^{b} \\
(0.056)\end{array}$ & $\begin{array}{c}-0.047 \\
(0.036)\end{array}$ & $\begin{array}{c}-0.051 \\
(0.036)\end{array}$ & $\begin{array}{l}-0.039 \\
(0.034)\end{array}$ & $\begin{array}{c}0.022 \\
(0.072)\end{array}$ & $\begin{array}{c}0.013 \\
(0.070)\end{array}$ \\
\hline Shengen dum. & $\begin{array}{c}0.040 \\
(0.040)\end{array}$ & $\begin{array}{l}-0.047^{c} \\
(0.028)\end{array}$ & $\begin{array}{l}-0.049^{c} \\
(0.028)\end{array}$ & $\begin{array}{l}-0.048^{c} \\
(0.027)\end{array}$ & $\begin{array}{l}-0.013 \\
(0.050)\end{array}$ & $\begin{array}{c}-0.027 \\
(0.049)\end{array}$ \\
\hline EEA dum. & $\begin{array}{c}0.995^{a} \\
(0.094)\end{array}$ & $\begin{array}{c}0.411^{a} \\
(0.090)\end{array}$ & $\begin{array}{c}0.410^{a} \\
(0.090)\end{array}$ & $\begin{array}{c}0.421^{a} \\
(0.080)\end{array}$ & $\begin{array}{c}0.579^{a} \\
(0.102)\end{array}$ & $\begin{array}{c}0.605^{a} \\
(0.098)\end{array}$ \\
\hline EU-Switzerland RTA dum. & $\begin{array}{c}0.782^{a} \\
(0.100)\end{array}$ & $\begin{array}{l}-0.026 \\
(0.093)\end{array}$ & $\begin{array}{c}-0.029 \\
(0.092)\end{array}$ & $\begin{array}{l}-0.027 \\
(0.088)\end{array}$ & $\begin{array}{c}0.363^{a} \\
(0.109)\end{array}$ & $\begin{array}{c}0.329^{a} \\
(0.109)\end{array}$ \\
\hline EU-Turkey RTA dum. & $\begin{array}{l}-0.243^{c} \\
(0.124)\end{array}$ & $\begin{array}{c}0.145 \\
(0.107) \\
\end{array}$ & $\begin{array}{c}0.137 \\
(0.108) \\
\end{array}$ & $\begin{array}{c}0.200^{b} \\
(0.098)\end{array}$ & $\begin{array}{c}0.013 \\
(0.192) \\
\end{array}$ & $\begin{array}{c}0.027 \\
(0.203) \\
\end{array}$ \\
\hline Observations & 849147 & 1316900 & 849147 & 849147 & 1316900 & 849147 \\
\hline R2 & 0.858 & 0.991 & 0.991 & 0.985 & 0.881 & 0.882 \\
\hline RMSE & 1.254 & & & 0.266 & & \\
\hline
\end{tabular}

We now proceed to presenting results obtained with different estimators. PPML has been made popular as an alternative to linear-in-logs OLS by Santos Silva and Tenreyro (2006). While the original motivation was to correct for a potential bias related to heteroskedasticity arising through log-linearization, it was also made attractive by its ability to handle zeroes.

Theoretical consistency requires to include a very large set of fixed effects: one for each importer-year, exporter-year, and pair of countries in a panel that spans over more than 60 years. This is made feasible in OLS through recent advances in this 
type of estimation. ${ }^{4}$ This advance in estimation of high-dimensional fixed effects has now been ported to the PPML estimator. ${ }^{5}$

Column (1) of Table 4 replicates our preferred estimation with OLS. Comparing column (1) to column (3) shows the pure effect of switching from OLS to PPML, since it keeps the zeroes out of the regression for PPML. The effect of RTAs is made very close to zero by this method. Most important for our purposes, the EU effects are reduced but still (very) significantly positive. Maintaining zeroes in the sample in column (2) does not change matters substantially compared to column (3) as is frequently the case. Note that our insignificant results regarding the trade effect of the euro in column (3) are close to Larch et al. (2017) but not when using linear-in-logs OLS. One noticeable difference is that our paper accounts for the deepening of the European union, through in particular the implementation of the single market beginning in 1993. It seems to be of utmost importance when measuring the trade impact of the creation in 1999 of the euro area, whose members all belong to the EU.

Table 4 also shows large variance in the estimates of GATT / WTO, shared currency, EU-Switzerland and EU-Turkey when switching estimator from OLS to PPML. Those differences, sometimes large, have already been documented in the literature, in particular related to colonial linkages. As emphasized by Eaton et al. (2013) and Head and Mayer (2014), when studying the discrepancies between PPML and linear-in-logs OLS estimators, it is useful to consider how different are their first order conditions. The former works with deviations from levels of the flow with respect to its prediction, while the latter works with log deviations. PPML will naturally tend therefore to put more weight on pairs of countries with large levels of trade. If ever those countries have a true underlying effect of RTA that differs from the rest of the sample, it will lead PPML to give an overall coefficient closer to this specific part of the sample (large flows) than to the unweighted average effect (this point was made and demonstrated by Monte Carlo simulations in Head and Mayer (2014)).

One way to see this effect at work is to apply weights proportional to levels of flows to the linear-in-logs specification. This is done in column (4) which shows results strikingly closer to column (3). A confirmation of that pattern is given in columns (5) and (6), which runs PPML on trade shares (bilateral imports divided by total imports) rather than trade flows. This is a method suggested by Eaton et al. (2013) so as to estimate their model of trade with discrete numbers of firms.

\footnotetext{
${ }^{4}$ The reghdfe Stata program that we use is particularly helpful in this respect.

${ }^{5}$ The ppml_panel_sg Stata program developed by Larch et al. (2017).
} 
This specification also will naturally give less weight to large flows in levels, since it works with trade shares for a given importer. The natural comparison is now column (6) and column (1). Those are indeed much more proximate. To sum up, linear-in-logs and PPML estimates of RTA effects (and of currency effects, see Santos Silva and Tenreyro (2010) or Larch et al. (2017) for instance) can be quite different. This is mainly due to how those estimators weight different parts of the sample, and in particular dyads with large predicted flows, which seem to generally have lower trade elasticities (Novy (2013) and Bas et al. (2017) are two papers providing (different) theoretical models featuring this type of heterogeneous elasticities together with empirical evidence). Our counterfactuals will therefore also consider results using PPML estimates of the EU effect on trade.

Figure 2 shows the evolution of the EU trade effect over time under several specifications. Panel (a) runs a regression where an EC/EU membership dummy is interacted with year dummies since 1958. It also highlights two important dates: i) 1968 which marks the end of the phasing-in period (after this, tariffs are uniformly zero among members), ii) 1993 which is the date of entry into force of the Single Market. Panel (b) is reporting coefficients and confidence intervals for the same setup using PPML. The overall trend is quite clear in both cases: the effect of the EU is large and getting larger over time. Both panels also show an impressive drop in years 1973/1974. A likely explanation for this drop is that this year is also the one where the United Kingdom, Ireland and Denmark enter the EC. Since those (and the UK in particular) should be initially trading relatively little with incumbent members, the composition effect might drive the overall effect down. This is investigated in panels (c) and (d) of the figure, where we introduce specific effects for EC/EU enlargements occurring in 1973 and later (1981, 1986, 1995, 2004 and 2007 for our sample). Those consists of dummies turning one between new members and incumbents during the first ten years of each enlargement. It is very clear that the drop in the 70s is mostly explained by the entry of the UK, Ireland and Denmark. The overall effect (in black dots, now purged from enlargements) is much smoother under that configuration. Note that accounting for the entries is particularly important for PPML. The difference is especially strong in 1973 and 1986. This is to be expected based on the different weighting properties of linearin-logs OLS vs PPML mentioned above. The entry of UK and Spain in those two years yields large expected flows in those two years, to which PPML gives more weight. We attribute what remains of the drop in the seventies to the first oil shock, which naturally should redirect trade towards non-member countries.

The trade impact of the single market strengthens over time, as expected from its gradual implementation. The effects are large at the end of the estimation period 
Figure 2 - The effect of European integration on trade over time

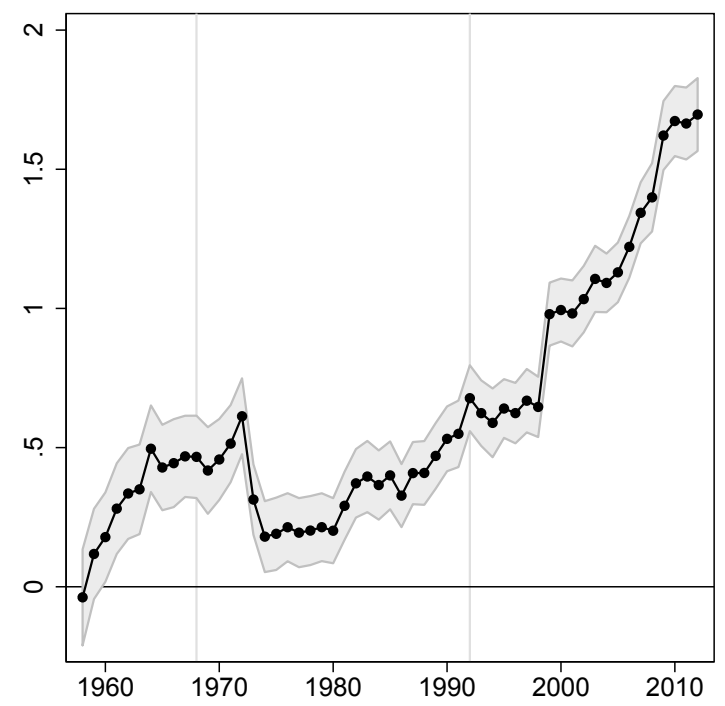

(a) OLS

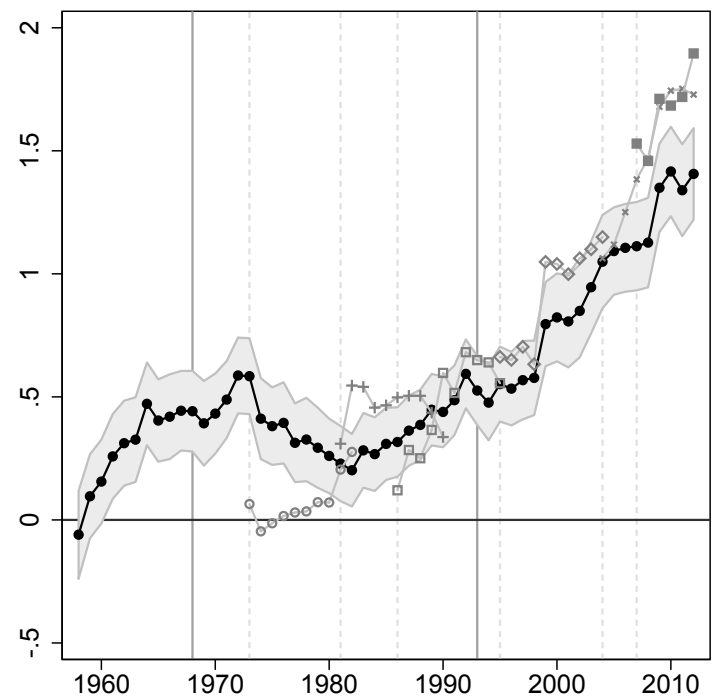

(c) Controling for enlargments: OLS

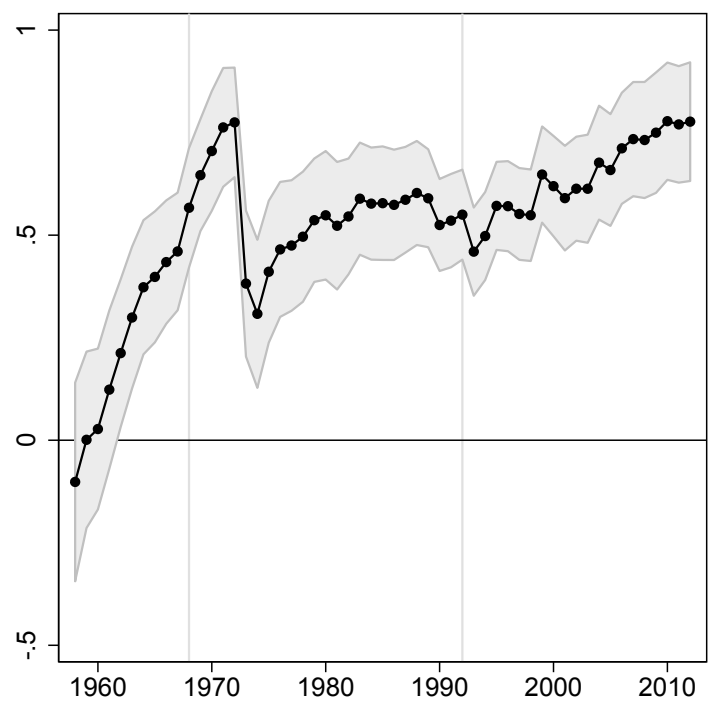

(b) PPML

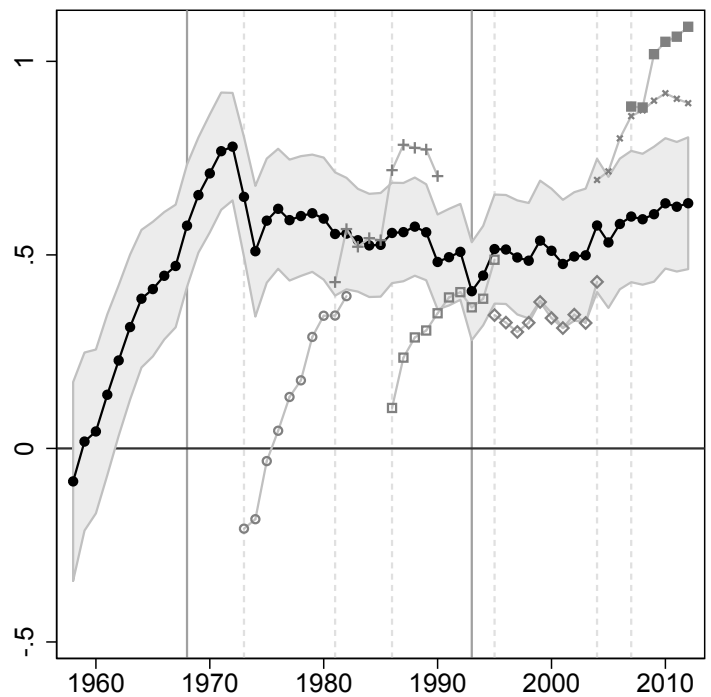

(d) Controling for enlargments: PPML Note: Table A.1 in Appendix provides the full set of coefficient estimates. Panels (c) and (d) introduce specific effects for EC/EU enlargements occurring in 1973 and later (1981, 1986, 1995, 2004 and 2007 for our sample), consisting of dummies turning one between new members and incumbents during the first ten years of each enlargement. 
for both the OLS and the PPML estimates: the specification from Figure 2.c yields a coefficient on the EU of 1.406 in 2012, while the PPML specification in Figure 2.d yields a coefficient of 0.633. Baier et al. (2014) also find that the effect of deep agreements takes time to be fully realized. They report that deep integration approximately doubles trade after ten years. Table A.1 in our Appendix provides the full set of EU coefficient estimates over time. During the 1992-2002 period, the excess trade attributed to EU is multiplied by $\exp (0.849-0.593)=1.29$, while over 15 years, we obtain a $\exp (1.112-0.593)=1.68$ surplus in trade.

\subsubsection{Trade in services}

We last turn to trade in services. The traditional gravity variables in column (1) have the expected effects, but the RTA dummy has a much dampened and more volatile influence. The EU dummy keeps a positive, although smaller, influence on trade over all specifications, including our preferred one in column (4). As stated above, this is a much reduced sample, which starts in the beginning of the 1990s, and covers a much smaller number of countries. We therefore report in column (7) results for goods on the same sample as services for appropriate comparison. Both regressions have the full set of fixed effects and use OLS. RTAs have a smaller effect, around $6 \%$, on trade in services that what we find for trade in goods (9\%). The EU still exhibits a substantially larger effect than the average agreement on flows of services (note that this is the equivalent of EU post-92 since the sample starts in 1992). Note that the relative impact of the Single market compared to a regular RTA is similar to one estimated for trade in goods in column (3) of Table 1: the EU post-92 increases three times more trade in services than a regular RTA. The comparison with goods in column (7) makes it clear that most of the reduced effects from previous columns comes from the shortened panel (Limão (2016) also underlines that shorter panel are unable to capture the long term effect of RTAs). Overall, we find an almost twice lower impact of the EU and regular RTAs on trade in services than trade in goods.

\section{Quantifying the welfare impact of European integration}

\subsection{General Equilibrium Trade Impact and Welfare changes}

With the gravity estimates of EU effects in hand, we now turn to simulations of different scenarios of EU disintegration, which also informs us about the gains associated with the current situation. Those exercises rely heavily on the recent stream of work quantifying the impact of various trade policy scenarios using the gravity equation as a building block for the construction of counterfactuals. Costinot and 
Table 5 - Gravity results of European integration in services

\begin{tabular}{|c|c|c|c|c|c|c|}
\hline $\begin{array}{l}\text { Sample } \\
\text { Flow }\end{array}$ & (1) & (2) & $\begin{array}{c}\text { (3) } \\
\text { Services } \\
\text { Services }\end{array}$ & (4) & (5) & $\begin{array}{c}(6) \\
\text { Services } \\
\text { Goods }\end{array}$ \\
\hline In Pop, origin & $\begin{array}{c}0.879^{a} \\
(0.015)\end{array}$ & $\begin{array}{l}-1.091^{a} \\
(0.251)\end{array}$ & & & & \\
\hline In Pop, dest & $\begin{array}{c}0.879^{a} \\
(0.014)\end{array}$ & $\begin{array}{c}1.033^{a} \\
(0.284)\end{array}$ & & & & \\
\hline In GDP/Pop, origin & $\begin{array}{c}1.366^{a} \\
(0.024)\end{array}$ & $\begin{array}{c}0.559^{a} \\
(0.039)\end{array}$ & & & & \\
\hline In GDP/Pop, dest & $\begin{array}{c}1.395^{a} \\
(0.024)\end{array}$ & $\begin{array}{c}0.889^{a} \\
(0.046)\end{array}$ & & & & \\
\hline In distance(avg) & $\begin{array}{l}-0.950^{a} \\
(0.033)\end{array}$ & & $\begin{array}{c}-1.296^{a} \\
(0.060)\end{array}$ & & & \\
\hline Shared Border dum. & $\begin{array}{c}0.417^{a} \\
(0.110)\end{array}$ & & $\begin{array}{c}0.409^{a} \\
(0.133)\end{array}$ & & & \\
\hline Shared language dum. & $\begin{array}{c}0.491^{a} \\
(0.112)\end{array}$ & & $\begin{array}{l}-0.136 \\
(0.126)\end{array}$ & & & \\
\hline Shared legal origin dum. & $\begin{array}{c}0.198^{a} \\
(0.053)\end{array}$ & & $\begin{array}{c}0.421^{a} \\
(0.045)\end{array}$ & & & \\
\hline Colonial history dum. & $\begin{array}{c}1.280^{a} \\
(0.234)\end{array}$ & & $\begin{array}{c}0.841^{a} \\
(0.216)\end{array}$ & & & \\
\hline Ever sibling dum. & $\begin{array}{c}1.017^{a} \\
(0.098)\end{array}$ & & $\begin{array}{c}0.417^{a} \\
(0.126)\end{array}$ & & & \\
\hline RTA dum. & $\begin{array}{l}-0.044 \\
(0.062)\end{array}$ & $\begin{array}{c}0.047 \\
(0.036)\end{array}$ & $\begin{array}{c}0.107 \\
(0.093)\end{array}$ & $\begin{array}{c}0.072 \\
(0.044)\end{array}$ & $\begin{array}{c}0.060 \\
(0.046)\end{array}$ & $\begin{array}{c}0.093^{b} \\
(0.039)\end{array}$ \\
\hline EU dum. & $\begin{array}{l}0.121^{c} \\
(0.072)\end{array}$ & $\begin{array}{c}0.183^{a} \\
(0.054)\end{array}$ & $\begin{array}{l}-0.174 \\
(0.123)\end{array}$ & $\begin{array}{c}0.174^{b} \\
(0.071)\end{array}$ & $\begin{array}{l}0.177^{b} \\
(0.070)\end{array}$ & $\begin{array}{c}0.320^{a} \\
(0.060)\end{array}$ \\
\hline Both GATT dum. & $\begin{array}{c}0.074 \\
(0.082)\end{array}$ & $\begin{array}{c}0.210^{a} \\
(0.053)\end{array}$ & $\begin{array}{l}-0.006 \\
(0.325)\end{array}$ & $\begin{array}{c}0.217 \\
(0.312)\end{array}$ & $\begin{array}{c}0.219 \\
(0.312)\end{array}$ & $\begin{array}{c}0.258 \\
(0.249)\end{array}$ \\
\hline Euro area dum. & $\begin{array}{l}-0.181^{a} \\
(0.061)\end{array}$ & $\begin{array}{c}0.031 \\
(0.050)\end{array}$ & $\begin{array}{c}-0.355^{a} \\
(0.082)\end{array}$ & $\begin{array}{c}0.043 \\
(0.057)\end{array}$ & $\begin{array}{c}0.052 \\
(0.060)\end{array}$ & $\begin{array}{c}0.026 \\
(0.047)\end{array}$ \\
\hline Shengen dum. & & & & & $\begin{array}{l}-0.032 \\
(0.042)\end{array}$ & \\
\hline EEA dum. & & & & & $\begin{array}{l}0.231^{c} \\
(0.122)\end{array}$ & \\
\hline EU-Switzerland RTA dum. & & & & & $\begin{array}{l}-0.001 \\
(0.100)\end{array}$ & \\
\hline EU-Turkey RTA dum. & & & & & $\begin{array}{c}0.071 \\
(0.117)\end{array}$ & \\
\hline Observations & 35874 & 35874 & 35963 & 35927 & 35927 & 34903 \\
\hline $\mathrm{R} 2$ & 0.776 & 0.515 & 0.865 & 0.965 & 0.965 & 0.971 \\
\hline RMSE & 1.330 & 0.603 & 1.070 & 0.568 & 0.568 & 0.506 \\
\hline Origin $\times$ year and dest $\times$ year $F E$ & - & - & Yes & Yes & Yes & Yes \\
\hline Country pair FE & - & Yes & - & Yes & Yes & Yes \\
\hline Year FE & Yes & Yes & - & - & - & - \\
\hline
\end{tabular}


Rodriguez-Clare (2014) give a full coverage of this line of research, considering many cases, varying in particular market structure, the presence of intermediates, the number of sectors and factors considered. We focus on the case relevant for i) multiple sectors (aggregated with Cobb-Douglas preferences), ii) including tradable intermediates and iii) perfect or Bertrand competition (à la Bernard et al. (2003)) as our benchmark.

Simplifying equation (28) of Costinot and Rodriguez-Clare (2014) for our benchmark case described above, the welfare gains applying to the class of trade models obeying structural gravity can be written as

$$
\hat{C}_{n}=\prod_{s}\left(\hat{\pi}_{n n, s}\right)^{-\beta_{n, s} a_{n, s s} / \varepsilon_{s}}
$$

where hats denote percentage changes $\left(\hat{C}_{n}=\frac{C_{n}^{\prime}}{C_{n}}\right.$, with $C_{n}$ the initial welfare and $C_{n}^{\prime}$ the new one after policy change). In terms of welfare determinants, $\pi_{n n, s}$ denotes the domestic share in total expenditure of country $n$ in sector $s, a_{n, s s}$ are the elements of an inverse Leontief matrix of input-output linkages $\left(I-A_{n}\right)^{-1}, \varepsilon_{s}<0$ is the trade elasticity relevant in the sector, and $\beta_{n, s}$ is the exogenous preference parameter for $s$ in $n$, such that $\sum_{s} \beta_{n, s}=1$. We simplify the structure of $1 / 0$ linkages, as in Dekle et al. (2007) assuming that intermediate inputs are mostly sourced from the sector itself $\left(\alpha_{n, s s^{\prime}}=0\right.$ if $\left.s \neq s^{\prime}\right) . A_{n}$ is therefore diagonal with elements that are technology parameter $\alpha_{n, s s}$.

In the version without intermediate goods, equation (5) reduces to:

$$
\hat{C}_{n}=\prod_{s}\left(\hat{\pi}_{n n, s}\right)^{-\beta_{n, s} / \varepsilon_{s}},
$$

in which we can recognize the well-known result by Arkolakis et al. (2012) that welfare changes of any policy counterfactual can be captured by a very small number of sufficient statistics, among which the change in domestic expenditure share and the trade elasticity are key.

Quantifying the welfare changes implied by various scenarios therefore implies a computation of equilibrium counterfactual trade shares, which will yield $\pi_{n n, s}^{\prime}$, following a change in trade costs from $\phi_{n i, s}$ to $\phi_{n i, s}^{\prime}$ (recalling that $\phi_{n i} \equiv \tau_{n i}^{\epsilon}$ ). Adopting terminology from Head and Mayer (2014), and using equation (1), we can compute the "General Equilibrium Trade Impact (GETI)" of a change in EU membership (from $\mathrm{EU}_{n i}$ to $\mathrm{EU}_{n i}^{\prime}$ ) as:

$$
\hat{\pi}_{n i, s} \hat{X}_{n, s}=\frac{X_{n i, s}^{\prime}}{X_{n i, s}}=\underbrace{\exp \left[\beta_{E U, s}\left(\mathrm{EU}_{n i}^{\prime}-\mathrm{EU} U_{n i}\right)\right]}_{\text {Partial Trade Impact (gravity estimate) }} \times \frac{\hat{Y}_{i, s} \hat{X}_{n, s}}{\hat{\Omega}_{i, s} \hat{\Phi}_{n, s}},
$$


in which $\beta_{E U, S}$ is our gravity estimate of the "Partial Trade Impact (PTI)" of being a member of the EU (partial because it controls for MR and income terms through fixed effects, but does not solve for the equilibrium value of those following a change in membership). A proper assessment of general equilibrium effects of the EU construction or dissolution therefore need to solve for counterfactual changes in multilateral resistance terms and GDPs to assess the trade impact of different scenarios on trade by members and non-members. To this purpose, we can go back to structural gravity, which in this class of trade models also writes:

$$
X_{n i, s}=\pi_{n i, s} X_{n, s}=\frac{\left(w_{i, s}^{\mu_{s}} P_{i, s}^{1-\mu_{s}} \tau_{n i, s}\right)^{\varepsilon_{s}}}{\sum_{\ell}\left(w_{\ell, s}^{\mu_{s}} P_{\ell, s}^{1-\mu_{s}} \tau_{n \ell, s}\right)^{\varepsilon_{s}}} X_{n, s}
$$

where $\mu_{s}$ is the share of value added in output of sector $s$, applying to the ideal price index of intermediates produced in $i, P_{i, s}$, and to the price of the composite primary factor used in production in $i$ for sector $s, w_{i, s}$. Assuming $Y_{i, s}=w_{i, s} L_{i, s}$, with $L_{i, s}$ constant, we obtain:

$$
\frac{\pi_{n i, s}^{\prime}}{\pi_{n i, s}}=\hat{\pi}_{n i, s}=\frac{\left(\hat{Y}_{i, s}^{\mu_{s}} \hat{P}_{i, s}^{1-\mu_{s}} \hat{\tau}_{n i, s}\right)^{\varepsilon_{s}}}{\sum_{\ell} \pi_{n \ell, s}\left(\hat{Y}_{\ell, s}^{\mu_{s}} \hat{P}_{\ell, s}^{1-\mu_{s}} \hat{\tau}_{n \ell, s}\right)^{\varepsilon_{s}}} .
$$

Assuming that trade balances are exogenously given on a per capita basis, $X_{n, s}=$ $w_{n, s} L_{n, s}\left(1+d_{n, s}\right)$, we have that $\hat{X}_{n, s}=\hat{w}_{n, s}=\hat{Y}_{n, s}$. Using the market clearing condition that $Y_{i, s}^{\prime}=\sum_{n} \pi_{n i, s}^{\prime} X_{n, s}^{\prime}$, one can solve for the changes in production of each origin country:

$$
\hat{Y}_{i, s}=\frac{1}{Y_{i, s}} \sum_{n} \hat{\pi}_{n i, s} \pi_{n i, s} \hat{Y}_{n, s} X_{n, s}
$$

We consider counterfactual scenarios where the EU is replaced by a "normal", shallow-type, regional agreement, or reverts to WTO rules. The algorithm solving for equilibrium changes in trade shares, income, output and welfare follows three steps: ${ }^{6}$

1. calculate $\mathrm{PTI}_{n i, s}=\hat{\phi}_{n i, s}=\exp \left(-\beta_{E U, S}\right)$ for the ni pairs in which $\mathrm{EU}_{n i}=1$ and $\hat{\phi}_{n i, s}=1$ for all other pairs;

2. plug estimated $\hat{\phi}_{n i, s}$ (along with initial values of $Y_{i, s}, X_{n, s}$, and the $\pi_{n i, s}$ ) into equation (10), substitute $\hat{\phi}_{n i, s}$ and $\hat{Y}_{i, s}^{\varepsilon_{s}}$ into equation (9) to get the matrix of trade changes and iterate using a dampening factor until $\hat{\pi}_{n i, s}$ stops changing;

\footnotetext{
${ }^{6}$ Since we assume that intermediate goods are consumed from the sector itself only, the computation can be run separately for each sector $s$.
} 
3. calculate the GETI, $\hat{\pi}_{n i, s} \hat{Y}_{n, s}$, for each country pair and the change in intranational trade $\hat{\pi}_{n n, s}$. Combined with estimates of $\beta_{n, s}, a_{n, s s}$ from data and $\varepsilon_{s}$ from the literature, calculate welfare changes using (5) or (6) depending upon the case under consideration.

\subsection{Data}

We use data from the World Input-Output Database (WIOD) developed by Timmer et al. (2015), which provides production and trade data for 43 countries and 56 2-digit (ISIC rev4) sectors covering the whole economy. We use data for 2014 , the most recent year available. ${ }^{7}$ We aggregate the data into three broad sectors: goods, tradable services and non-tradable services. ${ }^{8}$ The share of intermediate inputs in production of each sector is taken from WIOD as the world average of value added to production by sector: $\mu_{\text {good }}=0.321$ and $\mu_{\text {busserv }}=0.548$. The trade elasticity $\epsilon_{s}=5.03$ is taken from the preferred value reported in Head and Mayer (2014).

The estimate of the trade impact $\beta_{E U, s}$ is taken from section 2, and encompasses the full effect of the single market membership, i.e. the EU estimated direct impact at the end of the estimation period. For trade in goods, we use results from Figure 2.c, i.e. $\beta_{E U \text {,goods }}=1.406$ and $\beta_{R T A \text {,goods }}=0.391 .{ }^{9}$ As underlined in section 2 , the impact found on trade in services is about half the impact on trade in goods when estimated on the same sample (columns (4) and (6) in Table 5). We therefore assume $\beta_{E U \text {,serv }}=1.406 / 2=0.703$.

\subsection{The fit of Exact Hat Algebra: the case of the 2004 enlargement}

Our first exercise is to assess the goodness of fit of counterfactual analysis using the experiment of EU enlargement to 10 new members in 2004 . We want to see whether the model is doing a reasonable job at predicting the outcome of past liberalization episodes, i.e. how trade shares and output in Europe changed following the enlargement of the EU to Central and Eastern Europe.

\footnotetext{
${ }^{7}$ The data is extracted from the 2016 release of WIOD: http://www . wiod.org/release16.

${ }^{8}$ The goods sector includes agriculture, hunting, forestry and fishing, mining and quarrying and total manufactures, i.e. ISIC rev.4 sectors 01 to 33; the tradable services sector includes all business services, i.e. sectors 45 to 75; and non-tradable services includes all other services, i.e. electricity, gas and water supply (sectors 35-39), construction (41-43) and community, social and personal services (77 to 99 ).

${ }^{9}$ We disregard the euro area membership since we find an insignificant impact on trade after 2009.
} 
The exercise runs as follows: we take as our baseline year what is reported by WIOD in 2003 (one year prior to enlargement), combined with PTI estimates from the previous section, and compare trade shares predicted following the 2004 enlargement $\left(\pi_{n i, s}^{\prime}\right)$ to actual trade shares in $2014 .{ }^{10}$ Since the model also includes an adjustment of each country's production, we can also assess the goodness of fit on production data as measured by shares in total EU output by sector.

Table 6 - Goodness of fit for the 2004 enlargement

\begin{tabular}{|c|c|c|c|c|c|c|c|c|c|c|c|c|}
\hline & (1) & (2) & (3) & (4) & (5) & (6) & (7) & (8) & (9) & (10) & (11) & (12) \\
\hline Sector & good & serv & good & good & good & good & good & serv & serv & serv & serv & serv \\
\hline Level/diff & level & level & diff & diff & diff & diff & diff & diff & diff & diff & diff & diff \\
\hline Comparison year & 2014 & 2014 & 2014 & 2014 & 2014 & 2014 & 2014 & 2014 & 2014 & 2014 & 2014 & 2014 \\
\hline Sample & & & & eu25 & enlarg04 & intra & $\begin{array}{l}\text { intra no } \\
\text { outlier* }\end{array}$ & & eu25 & enlarg04 & intra & $\begin{array}{l}\text { intra no } \\
\text { outlier* }\end{array}$ \\
\hline & \multicolumn{12}{|c|}{ Trade } \\
\hline $\mathrm{R} 2$ & 0.959 & 0.996 & 0.312 & 0.487 & 0.706 & 0.053 & 0.516 & 0.123 & 0.198 & 0.388 & 0.425 & 0.421 \\
\hline \multirow[t]{2}{*}{ Observations } & 1,936 & 1,936 & 1,936 & 625 & 400 & 10 & 9 & 1,936 & 625 & 400 & 10 & 9 \\
\hline & \multicolumn{12}{|c|}{ Share in EU-25 production } \\
\hline $\mathrm{R} 2$ & 0.997 & 0.999 & 0.771 & 0.771 & 0.948 & & 0.650 & 0.526 & 0.526 & 0.738 & & 0.082 \\
\hline Observations & 25 & 25 & 25 & 25 & 10 & & 9 & 25 & 25 & 10 & & 9 \\
\hline
\end{tabular}

Table 6 presents the R-squared from regressing predicted trade or production shares on observed counterparts in 2014. Such regressions are performed in level and differences with respect to 2003 (the data from which the simulation exercise is done). The fit of the model in levels is quite high which should not be too surprising since the cross-section part of the variance in bilateral trade is quite persistent and is a fundamental driver of the level attained in 2014 as predicted by the model. What is more difficult is for the model to have a good prediction of changes. Despite the myriad of country and country-pair specific shocks hitting over that 10-year period which can cause the realized change to deviate substantially from the prediction of the trade model, the simulation does a fairly good job at predicting patterns of changes. The prediction explains nearly $50 \%$ of the variance in changes of bilateral trade shares and nearly $80 \%$ of output changes in the EU over that decade (column 4).

Results can also be visually summarized in figure 3. In each panel, the $x$-axis plots the predicted change, while the y-axis is the true change. Panel (a) is trade

\footnotetext{
${ }^{10}$ Note that we consider further enlargements (in 2007 and 2013) as having taken place in the simulation exercise but do not consider those countries when considering the fit of our simulations since we want to compare long term adjustments.
} 
Figure 3 - Simulated vs real changes following the 2004 enlargement

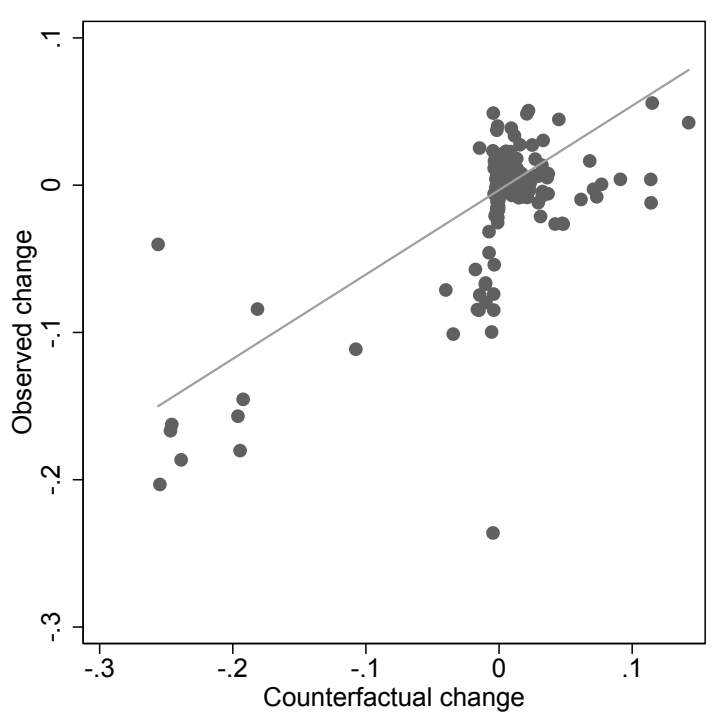

(a) Trade - Goods

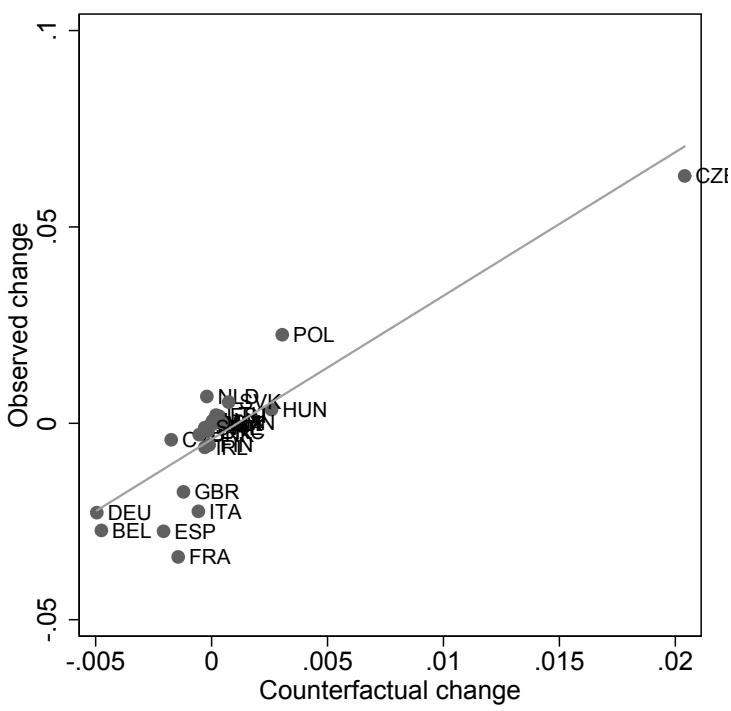

(c) Production (share EU-25) - Goods

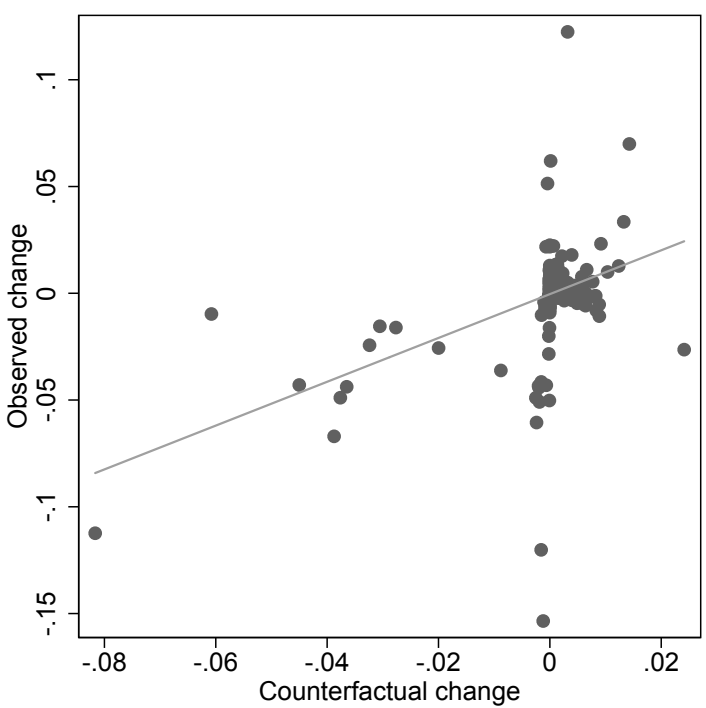

(b) Trade - Services

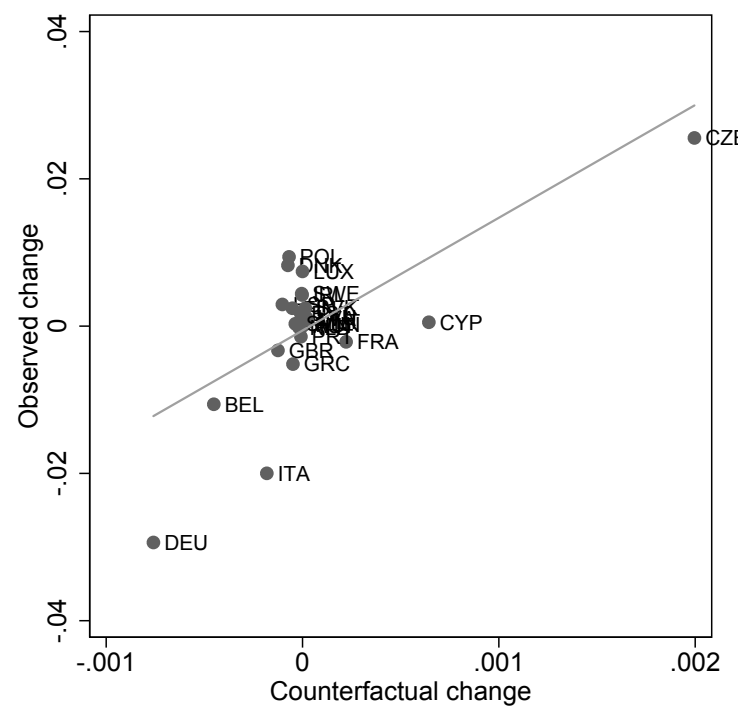

(d) Production (share EU-25) - Services Note: 
in goods, Panel (b) trade in services for all pairs of countries inside EU (after enlargement). Panels (c) and (d) show changes in output. While a host of other determinants explain actual changes, the model suggests that the enlargement can explain relatively well the central patterns of observed evolutions.

\section{The gains from the European Union}

We now turn to our counterfactuals meant to assess the gains from having the EU28 as it is against several alternatives (we defer the analysis of the impact of Brexit on gains from the EU to the next section). We consider two alternative scenarios to assess the gains from European integration. In a first counterfactual, we assume that the European Union is replaced by a regular/standard RTA, corresponding to the average effect of RTAs found in section 2. In a tougher scenario, we assume that trade between actual members of the European Union is governed by the Most Favored Nation tariffs in application of the World Trade Organization membership. ${ }^{11}$

\subsection{The trade effect of EU membership}

In this section, we present results obtained after computing the counterfactual (GETI) trade matrix under our scenario of EU returning to a "normal" RTA. Table 7 reports our results with the first columns showing the ratio of real to counterfactual trade flows. The first insight obtained from this table is that the European Union in its current state promotes trade strongly: total imports of goods by EU members increase by $36 \%$ on average in the RTA scenario presented in Table 7 , with a particularly large impact on small open economies and on Central and Eastern European countries. The import penetration ratio (total imports over consumption) in the goods sector is more than a quarter larger on average for EU countries compared to the counterfactual situation, with heterogeneous impacts depending on the initial geographical specialization of countries. Peripheral countries like Greece, Malta or Cyprus benefit less in terms of EU trade integration while small and Eastern European countries increase their trade openness in goods by figures often close to $50 \%{ }^{12}$ The impact on imports of services is lower, with an average increase of $29 \%$ involving a $21 \%$ larger import penetration ratio.

\footnotetext{
${ }^{11}$ Note that in this scenario, we abstract from tariffs revenues. It is unlikely to significantly change results since tariff reduction typically represent a small share of the reduction in trade costs between members as shown in section 2. Accounting for tariff revenues would however dampen the difference between the RTA and WTO scenarios.

${ }^{12}$ Note that the change in trade openness combines the direct impact on trade and the indirect one coming from endogenous GDP adjustments.
} 
Table 7 - The trade effect of EU integration (RTA scenario with intermediate inputs)

\begin{tabular}{|c|c|c|c|c|c|c|c|c|c|c|}
\hline \multirow{2}{*}{$\begin{array}{l}\text { Sector } \\
\text { Var. } \\
\text { Origin } \\
\text { State of the world }\end{array}$} & \multicolumn{3}{|c|}{$\begin{array}{c}\text { Goods } \\
\text { Imports } \\
\text { with/without EU }\end{array}$} & \multicolumn{2}{|c|}{$\begin{array}{c}\text { Goods } \\
\text { Import/ } \\
\text { consumption }\end{array}$} & \multicolumn{3}{|c|}{$\begin{array}{l}\text { Tradable Services } \\
\text { Imports } \\
\text { with/without EU }\end{array}$} & \multicolumn{2}{|c|}{$\begin{array}{c}\text { Tradable Services } \\
\text { Import/ } \\
\text { consumption }\end{array}$} \\
\hline & Total & EU & non $E U$ & $\begin{array}{l}\text { Total } \\
\text { With } \\
\text { EU }\end{array}$ & $\begin{array}{c}\text { Total } \\
\text { Without } \\
\text { EU }\end{array}$ & Total & EU & non EU & $\begin{array}{l}\text { Total } \\
\text { With } \\
\text { EU }\end{array}$ & $\begin{array}{c}\text { Total } \\
\text { Without } \\
\text { EU }\end{array}$ \\
\hline AUT & $152 \%$ & $202 \%$ & $82 \%$ & $60 \%$ & $41 \%$ & $132 \%$ & $156 \%$ & $95 \%$ & $13 \%$ & $10 \%$ \\
\hline BEL & $144 \%$ & $221 \%$ & $89 \%$ & $72 \%$ & $56 \%$ & $126 \%$ & $156 \%$ & $96 \%$ & $24 \%$ & $19 \%$ \\
\hline BGR & $128 \%$ & $209 \%$ & $83 \%$ & $55 \%$ & $43 \%$ & $136 \%$ & $160 \%$ & $98 \%$ & $11 \%$ & $8 \%$ \\
\hline CYP & $93 \%$ & $154 \%$ & $59 \%$ & $68 \%$ & $63 \%$ & $137 \%$ & $166 \%$ & $102 \%$ & $18 \%$ & $13 \%$ \\
\hline CZE & $164 \%$ & $228 \%$ & $92 \%$ & $61 \%$ & $41 \%$ & $125 \%$ & $146 \%$ & $90 \%$ & $14 \%$ & $11 \%$ \\
\hline DEU & $146 \%$ & $226 \%$ & $93 \%$ & $46 \%$ & $33 \%$ & $122 \%$ & $150 \%$ & $94 \%$ & $11 \%$ & $9 \%$ \\
\hline DNK & $140 \%$ & $203 \%$ & $81 \%$ & $59 \%$ & $44 \%$ & $119 \%$ & $157 \%$ & $96 \%$ & $19 \%$ & $16 \%$ \\
\hline ESP & $138 \%$ & $240 \%$ & $95 \%$ & $39 \%$ & $29 \%$ & $130 \%$ & $157 \%$ & $96 \%$ & $6 \%$ & $5 \%$ \\
\hline EST & $133 \%$ & $195 \%$ & $78 \%$ & $71 \%$ & $56 \%$ & $139 \%$ & $154 \%$ & $94 \%$ & $16 \%$ & $11 \%$ \\
\hline FIN & $143 \%$ & $222 \%$ & $89 \%$ & $44 \%$ & $31 \%$ & $116 \%$ & $147 \%$ & $89 \%$ & $13 \%$ & $11 \%$ \\
\hline FRA & $135 \%$ & $212 \%$ & $85 \%$ & $47 \%$ & $35 \%$ & $128 \%$ & $161 \%$ & $99 \%$ & $8 \%$ & $6 \%$ \\
\hline GBR & $116 \%$ & $198 \%$ & $81 \%$ & $47 \%$ & $39 \%$ & $131 \%$ & $165 \%$ & $101 \%$ & $8 \%$ & $6 \%$ \\
\hline GRC & $110 \%$ & $201 \%$ & $79 \%$ & $46 \%$ & $40 \%$ & $118 \%$ & $152 \%$ & $92 \%$ & $10 \%$ & $8 \%$ \\
\hline HRV & $135 \%$ & $195 \%$ & $79 \%$ & $54 \%$ & $40 \%$ & $126 \%$ & $154 \%$ & $94 \%$ & $12 \%$ & $10 \%$ \\
\hline HUN & $152 \%$ & $214 \%$ & $86 \%$ & $69 \%$ & $50 \%$ & $133 \%$ & $158 \%$ & $97 \%$ & $21 \%$ & $16 \%$ \\
\hline IRL & $132 \%$ & $217 \%$ & $83 \%$ & $79 \%$ & $66 \%$ & $109 \%$ & $155 \%$ & $96 \%$ & $52 \%$ & $48 \%$ \\
\hline ITA & $145 \%$ & $239 \%$ & $95 \%$ & $33 \%$ & $24 \%$ & $123 \%$ & $150 \%$ & $92 \%$ & $6 \%$ & $5 \%$ \\
\hline LTU & $126 \%$ & $220 \%$ & $88 \%$ & $68 \%$ & $57 \%$ & $121 \%$ & $161 \%$ & $100 \%$ & $19 \%$ & $15 \%$ \\
\hline LUX & $122 \%$ & $158 \%$ & $65 \%$ & $84 \%$ & $72 \%$ & $118 \%$ & $151 \%$ & $92 \%$ & $52 \%$ & $45 \%$ \\
\hline LVA & $128 \%$ & $190 \%$ & $76 \%$ & $64 \%$ & $51 \%$ & $139 \%$ & $160 \%$ & $99 \%$ & $11 \%$ & $8 \%$ \\
\hline MLT & $111 \%$ & $184 \%$ & $72 \%$ & $72 \%$ & $63 \%$ & $129 \%$ & $142 \%$ & $89 \%$ & $52 \%$ & $41 \%$ \\
\hline NLD & $142 \%$ & $241 \%$ & $97 \%$ & $67 \%$ & $53 \%$ & $130 \%$ & $175 \%$ & $107 \%$ & $19 \%$ & $15 \%$ \\
\hline POL & $154 \%$ & $230 \%$ & $93 \%$ & $43 \%$ & $29 \%$ & $144 \%$ & $180 \%$ & $109 \%$ & $10 \%$ & $7 \%$ \\
\hline PRT & $136 \%$ & $199 \%$ & $78 \%$ & $49 \%$ & $35 \%$ & $131 \%$ & $152 \%$ & $92 \%$ & $8 \%$ & $6 \%$ \\
\hline ROU & $135 \%$ & $204 \%$ & $82 \%$ & $39 \%$ & $28 \%$ & $146 \%$ & $174 \%$ & $106 \%$ & $9 \%$ & $6 \%$ \\
\hline SVK & $148 \%$ & $219 \%$ & $90 \%$ & $65 \%$ & $48 \%$ & $151 \%$ & $173 \%$ & $105 \%$ & $12 \%$ & $8 \%$ \\
\hline SVN & $149 \%$ & $216 \%$ & $86 \%$ & $68 \%$ & $50 \%$ & $132 \%$ & $161 \%$ & $97 \%$ & $14 \%$ & $11 \%$ \\
\hline SWE & $143 \%$ & $208 \%$ & $83 \%$ & $51 \%$ & $36 \%$ & $124 \%$ & $155 \%$ & $95 \%$ & $16 \%$ & $12 \%$ \\
\hline EU (mean) & $136 \%$ & $209 \%$ & $84 \%$ & $58 \%$ & $45 \%$ & $129 \%$ & $158 \%$ & $97 \%$ & $17 \%$ & $14 \%$ \\
\hline EU (median) & $137 \%$ & $210 \%$ & $83 \%$ & $59 \%$ & $42 \%$ & $129 \%$ & $156 \%$ & $96 \%$ & $13 \%$ & $10 \%$ \\
\hline
\end{tabular}

Note: Columns (1)-(3) and (6)-(8) present the ratio of actual imports (total, from EU countries and from extra EU countries respectively) to imports in the counterfactual without the EU. A ratio larger than $100 \%$ indicates that the EU increases imports from the specific origin. Columns (4) and (9) report the actual openness ratio (import/consumption) for goods or tradable services and columns (5) and (10) the openness ratio in the counterfactual case without the EU. 
An important difference between results in that section and the ones in section 2 lies in the indirect effects of the policy experiment (here EU integration). In the simple gravity setup of section 2, we estimate the direct impact ( $\mathrm{PTI}$ ) of the $\mathrm{EU}$, by neutralizing general equilibrium effects that happen through changes in multilateral resistance (MR) terms and changes in GDPs (shown in equation 7) through the use of origin $\times$ year and destination $\times$ year fixed effects. Results in Table 7 include all effects. The PTI and inward MR adjustment $(\Phi)$ effects have a strong connection to the trade creation / trade diversion effects from classical Vinerian analysis. Together they drive the re-orientation of expenditure sourcing by consumers in $n$ following the price changes implied by the policy experiment. The changes in GDP and outward multilateral resistance $(\Omega)$ drive the relative attractiveness of products proposed by country $i$.

In total, those effects imply a massive trade reallocation following the implementation (or collapse) of the EU. Bilateral imports of goods within the EU are on average close to twice as large compared to the counterfactual. The impact is particularly large for small open economies like the Netherlands, Belgium, Ireland, Slovakia, the Czech Republic or Poland. The impact on trade in services is much smaller (around 60\%), with increases caused by the EU ranging from $+80 \%$ for Poland to $+42 \%$ for Malta.

A key distinctive feature of the GETI approach, compared to traditional gravity is third-country effects, that are not quantifiable with gravity estimation. Those thirdcountry effects are subject to contradicting forces: the larger inward multilateral resistance in EU economies decreases trade from countries that do not benefit from preferential market access but the beneficial impact of the EU on member countries GDPs dampens this effect. Overall, Table 7 reveals that imports of goods from non-EU countries are expected to be on average 16\% lower than without the EU, but those imports are more stable for countries like the Netherlands, Italy or Poland. The same pattern holds for trade in services, even though to a lower extent with an average reduction of $3 \%$.

\subsection{Welfare gains by country member}

Table 8 reports the welfare gains in percent with two different scenarios and two different assumptions regarding whether intermediates are included or not in the model. Columns (1) and (2) consider the benchmark case with intermediates, when the two next columns omit them . Columns (1) and (3) consider the scenario under which a regular RTA replaces the EU, columns (2) and (4) take the most extreme route where EU countries return to the WTO option under which MFN tariffs 
replace the EU.

The main conclusion is very clear: all member countries unambiguously obtain sizable welfare gains from the EU as it is. The average gain across columns ranges from $2.3 \%$ to $8.2 \%$. Average gains are slightly lower on a weighted basis, ranging from $1.5 \%$ to $5.4 \%$, reflecting the lower dependence of large countries on international trade. In the type of model generating the equations we use for those calculations, there is an exact correspondence between welfare and real GDP. Hence, the EU on average has generated a permanent real GDP increase that is far from negligible. Those are comparative statics results and reflect long term changes in the level of GDP. The magnitude of the estimated gains however depends on the specific modeling assumptions regarding intermediate goods: whatever the scenario, gains from trade integration are substantially larger with intermediate goods (columns (1) and (2)) than without (columns (3) and (4)).

The counterfactual scenario where the EU is replaced by a normal RTA (i.e. dropping the "deep integration" characteristics such as free movement of labor, single market disposition regarding harmonization of norms, common competition policy with an objective to foster the EU integration, etc.) suggests that the Single market has generated an average $6.6 \%$ (4.4\% when weighted) permanent real GDP gain for EU countries (column (1) of table 8 ). In our view, it is not trivial to find an easily implementable policy change that would yield such a large average gain to European countries, with extremely robust empirical evidence (such as gravity for the present case of EU integration) backing up that policy. It is also important to note that both scenarios of alternative European integration would have been costly. While the alternative scenario of MFN status would of course have yielded the largest welfare losses, the persistence of a normal RTA would also have been very costly. Actually, the loss of deep integration represents more than four fifths $(4.4 / 5.5 \simeq 6.6 / 8.2 \simeq 80 \%)$ of the total effect of a return to WTO rules (clearly the worst case scenario).

Looking at the distribution of EU gains (or Non-Europe losses) across countries, again a very clear pattern emerges: small and open economies benefit more from EU integration as it is, and therefore would bear the largest costs under the disintegration scenarios. Particularly interesting is the case of the Eastern part of the EU. Hungary, Slovakia, Slovenia, Czech Republic are systematically ranked high on the list of countries that would suffer most from a collapse of the EU. Hungary for instance would loose $4.7 \%$ of real GDP under the most optimistic scenario, and $17.7 \%$ under the worst one. The most important losses are in the case where intermediate inputs are taken into account, which suggests that the deep input- 
Table 8 - Welfare gains from EU under different scenarios

\begin{tabular}{|c|c|c|c|c|}
\hline $\begin{array}{l}\text { Counterfactual } \\
\text { Assumption }\end{array}$ & $\begin{array}{l}\quad(1) \\
\text { to } \mathrm{RTA} \\
\text { with inte }\end{array}$ & $\begin{array}{c}(2) \\
\text { to MFN } \\
\text { mediates }\end{array}$ & $\begin{array}{c}(3) \\
\text { to RTA } \\
\text { without ir }\end{array}$ & $\begin{array}{l}(4) \\
\text { to MFN } \\
\text { ermediates }\end{array}$ \\
\hline AUT & $7,7 \%$ & $9,6 \%$ & $2,6 \%$ & $3,2 \%$ \\
\hline BEL & $8,5 \%$ & $10,7 \%$ & $3,0 \%$ & $3,8 \%$ \\
\hline$B G R$ & $6,7 \%$ & $8,1 \%$ & $2,2 \%$ & $2,7 \%$ \\
\hline CYP & $3,5 \%$ & $4,3 \%$ & $1,3 \%$ & $1,6 \%$ \\
\hline CZE & $10,8 \%$ & $13,3 \%$ & $3,6 \%$ & $4,4 \%$ \\
\hline DEU & $4,5 \%$ & $5,7 \%$ & $1,5 \%$ & $1,9 \%$ \\
\hline DNK & $5,6 \%$ & $6,9 \%$ & $2,0 \%$ & $2,4 \%$ \\
\hline ESP & $3,2 \%$ & $3,8 \%$ & $1,1 \%$ & $1,3 \%$ \\
\hline EST & $10,4 \%$ & $13,1 \%$ & $3,5 \%$ & $4,3 \%$ \\
\hline FIN & $4,1 \%$ & $5,0 \%$ & $1,4 \%$ & $1,7 \%$ \\
\hline FRA & $3,4 \%$ & $4,2 \%$ & $1,2 \%$ & $1,4 \%$ \\
\hline GBR & $2,3 \%$ & $2,8 \%$ & $0,8 \%$ & $1,0 \%$ \\
\hline GRC & $2,4 \%$ & $2,9 \%$ & $0,8 \%$ & $1,0 \%$ \\
\hline HRV & $6,1 \%$ & $7,5 \%$ & $2,0 \%$ & $2,5 \%$ \\
\hline HUN & $14,2 \%$ & $17,7 \%$ & $4,7 \%$ & $5,8 \%$ \\
\hline IRL & $6,8 \%$ & $8,5 \%$ & $2,7 \%$ & $3,4 \%$ \\
\hline ITA & $2,8 \%$ & $3,3 \%$ & $0,9 \%$ & $1,1 \%$ \\
\hline LTU & $8,7 \%$ & $10,7 \%$ & $2,9 \%$ & $3,6 \%$ \\
\hline LUX & $8,2 \%$ & $10,4 \%$ & $3,5 \%$ & $4,5 \%$ \\
\hline LVA & $6,4 \%$ & $7,8 \%$ & $2,2 \%$ & $2,6 \%$ \\
\hline MLT & $8,2 \%$ & $10,4 \%$ & $3,7 \%$ & $4,6 \%$ \\
\hline NLD & $7,6 \%$ & $9,3 \%$ & $2,7 \%$ & $3,3 \%$ \\
\hline POL & $6,0 \%$ & $7,4 \%$ & $2,0 \%$ & $2,4 \%$ \\
\hline PRT & $5,2 \%$ & $6,4 \%$ & $1,7 \%$ & $2,1 \%$ \\
\hline $\mathrm{ROU}$ & $4,6 \%$ & $5,6 \%$ & $1,5 \%$ & $1,9 \%$ \\
\hline SVK & $12,0 \%$ & $14,9 \%$ & $3,9 \%$ & $4,9 \%$ \\
\hline SVN & $10,5 \%$ & $13,1 \%$ & $3,5 \%$ & $4,3 \%$ \\
\hline SWE & $4,8 \%$ & $5,9 \%$ & $1,7 \%$ & $2,1 \%$ \\
\hline EU (weighted mean) & $4,4 \%$ & $5,5 \%$ & $1,5 \%$ & $1,9 \%$ \\
\hline EU (mean) & $6,6 \%$ & $8,2 \%$ & $2,3 \%$ & $2,8 \%$ \\
\hline
\end{tabular}

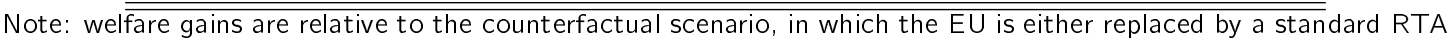
(columns (1) and (3)) or WTO rules (columns (2) and (4)). Welfare gains computed from equation (5) in columns (1)-(2) and equation (6) in columns (3)-(4). ${ }^{\star}$ weighted by share in consumption. 
output linkages that Eastern Europe has constructed with "Old Europe" would be very costly to undo.

We provide two sets of figures to illustrate how welfare gains from EU integration are related to country characteristics. Equation (5) states that the gains from a given reduction in international trade costs are increasing in the share of domestic trade affected. Larger countries (in terms of total production), which everything else equal consume more of their domestic production, indeed experience lower gains from European trade integration as shown in Figure 4 (panel a), while the opposite is true regarding countries initially more open to trade (Figure 4, panel b). In panels $c$ and $d$ of figure 4 , we relate those same welfare gains to "first nature" observables that are less endogenous to the EU integration process: population in panel $c$ and geographical remoteness in panel $d$. Again, large and/or peripheral countries that are expected to be less integrated in the European trade network are the ones where the gains from the EU are the more modest (still being far from trivial).

\subsection{Welfare gains under alternative gravity estimators}

Table 8 evaluates how sensitive are the welfare results to the method used in the gravity estimates of EU trade effects. As Table 4 shows, the OLS and PPML estimation of EU PTI effects can be quite different. EU estimates are still quite large and show a similarly increasing pattern, but the absolute level of the effect is smaller under PPML. There are two interpretations possible. The one we highlighted above, is that the key difference lies in the estimated trade elasticity: PPML focuses on the part of the sample with high predicted trade, those have theoretical reasons to have smaller response to trade costs (Novy (2013) and Bas et al. (2017) are two recent examples), therefore we should expect a smaller coefficient on $\mathrm{EU}$ integration. However the coefficient estimated is the interaction of two effects: the trade elasticity and the ad valorem equivalent of the change in trade costs due to implementation of the EU. In the case of the RTA scenario, the AVE of our OLS estimates combined with our benchmark trade elasticity $\varepsilon=5.03$ is $\mathrm{AVE}_{\mathrm{OLS}}=\exp (1.015 / 5.03)-1 \simeq 22 \%$. With the PPML estimate, keeping trade elasticity unchanged, it is $A V E_{P P M L}=\exp (0.661 / 5.03)-1 \simeq 14 \%$. At the opposite, keeping the AVE of OLS estimate and accounting for the difference in coefficients through trade elasticity alone gives an estimate of $\varepsilon_{\mathrm{PPML}}=0.661 / \ln (1.22)=3.27$. The consequence of either interpretation is very different in terms of welfare change. Very intuitively, the trade cost interpretation lowers welfare gains, since the EU is assumed to have done less in terms of trade costs reduction (compared to OLS estimates). The trade gains are about a third smaller in that case (column (2)). The 
Figure 4 - EU-membership welfare gains

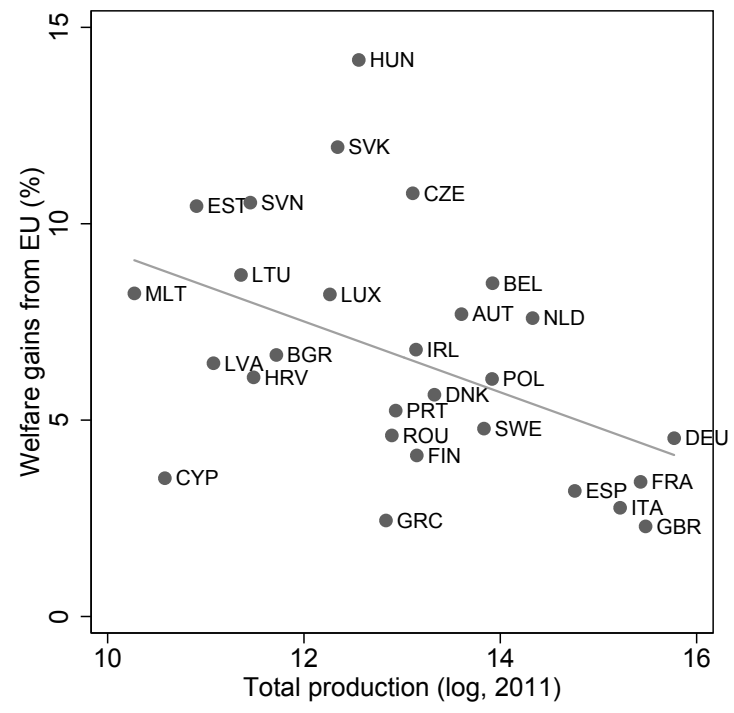

(a) Output and welfare

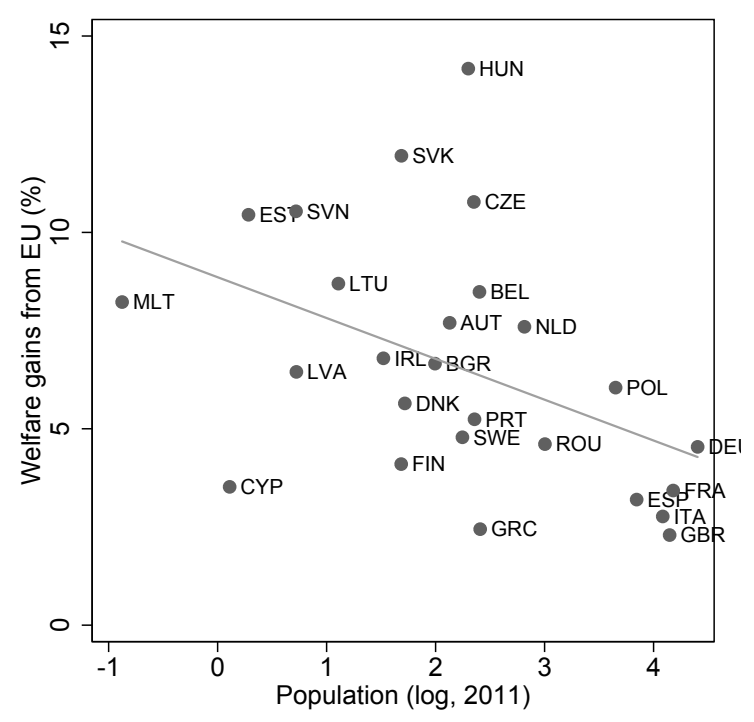

(c) Population and welfare

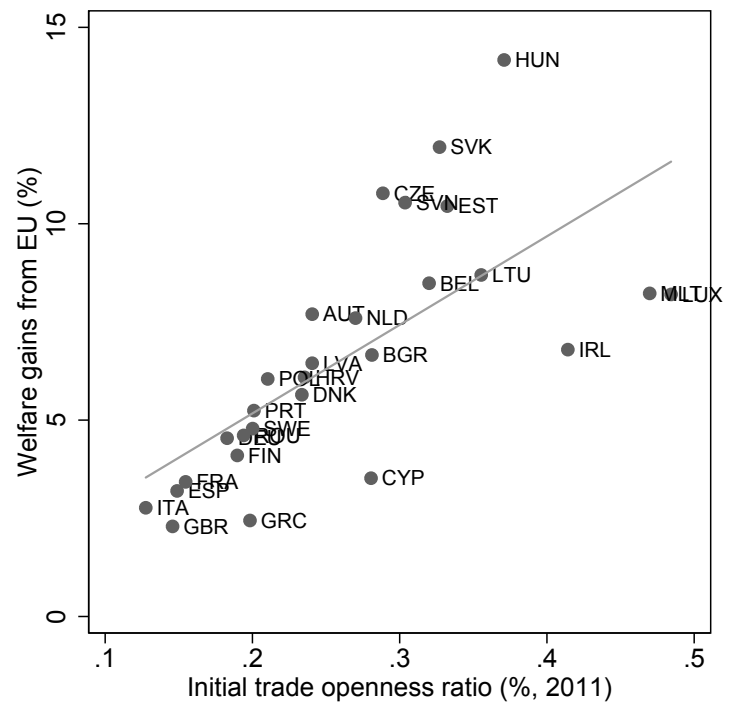

(b) Openness and welfare

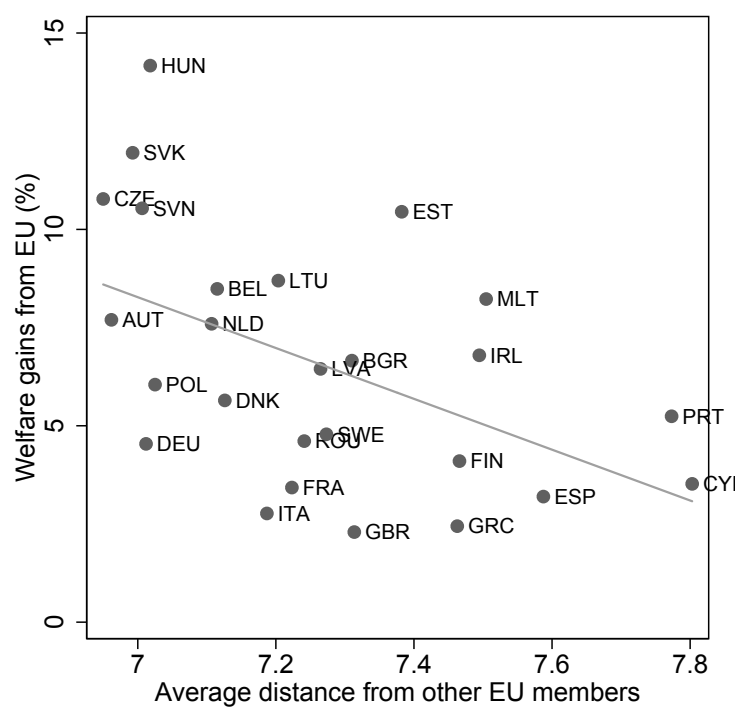

(d) Remoteness and welfare

Note: Welfare gains are from column (1) of Table 8: the standard RTA scenario with intermediate goods. Trade openness computed as total exports over production. 
Table 9 - Welfare gains from EU under different scenarios

\begin{tabular}{|c|c|c|c|}
\hline \multirow{3}{*}{$\begin{array}{l}\text { Counterfactual } \\
\text { Assumption } \\
\text { Estimate of EU PTI } \\
\text { trade impact: }\end{array}$} & $\begin{array}{c}(1) \\
\text { to RTA }\end{array}$ & $\begin{array}{c}(2) \\
\text { to RTA }\end{array}$ & $\begin{array}{c}(3) \\
\text { to RTA }\end{array}$ \\
\hline & \multicolumn{3}{|c|}{ with intermediates } \\
\hline & OLS & $\begin{array}{l}\text { PPML trade } \\
\text { costs }\end{array}$ & $\begin{array}{c}\text { PPML trade } \\
\text { elasticity }\end{array}$ \\
\hline AUT & $7,7 \%$ & $5,3 \%$ & $12,6 \%$ \\
\hline BEL & $8,5 \%$ & $5,8 \%$ & $13,6 \%$ \\
\hline BGR & $6,7 \%$ & $4,7 \%$ & $10,9 \%$ \\
\hline CYP & $3,5 \%$ & $2,5 \%$ & $5,9 \%$ \\
\hline CZE & $10,8 \%$ & $7,4 \%$ & $17,3 \%$ \\
\hline DEU & $4,5 \%$ & $3,2 \%$ & $7,4 \%$ \\
\hline DNK & $5,6 \%$ & $3,9 \%$ & $9,1 \%$ \\
\hline ESP & $3,2 \%$ & $2,3 \%$ & $5,1 \%$ \\
\hline EST & $10,4 \%$ & $7,2 \%$ & $17,1 \%$ \\
\hline FIN & $4,1 \%$ & $2,9 \%$ & $6,7 \%$ \\
\hline FRA & $3,4 \%$ & $2,4 \%$ & $5,5 \%$ \\
\hline GBR & $2,3 \%$ & $1,7 \%$ & $3,7 \%$ \\
\hline GRC & $2,4 \%$ & $1,7 \%$ & $4,1 \%$ \\
\hline HRV & $6,1 \%$ & $4,2 \%$ & $10,0 \%$ \\
\hline HUN & $14,2 \%$ & $9,7 \%$ & $23,0 \%$ \\
\hline IRL & $6,8 \%$ & $4,7 \%$ & $10,7 \%$ \\
\hline ITA & $2,8 \%$ & $2,0 \%$ & $4,4 \%$ \\
\hline LTU & $8,7 \%$ & $5,9 \%$ & $13,9 \%$ \\
\hline LUX & $8,2 \%$ & $5,5 \%$ & $13,3 \%$ \\
\hline LVA & $6,4 \%$ & $4,4 \%$ & $10,4 \%$ \\
\hline MLT & $8,2 \%$ & $5,5 \%$ & $13,6 \%$ \\
\hline NLD & $7,6 \%$ & $5,1 \%$ & $11,8 \%$ \\
\hline POL & $6,0 \%$ & $4,2 \%$ & $9,7 \%$ \\
\hline PRT & $5,2 \%$ & $3,7 \%$ & $8,6 \%$ \\
\hline ROU & $4,6 \%$ & $3,3 \%$ & $7,5 \%$ \\
\hline SVK & $12,0 \%$ & $8,2 \%$ & $19,4 \%$ \\
\hline SVN & $10,5 \%$ & $7,2 \%$ & $17,0 \%$ \\
\hline SWE & $4,8 \%$ & $3,3 \%$ & $7,8 \%$ \\
\hline EU (weighted mean) & $4,4 \%$ & $3,1 \%$ & $7,1 \%$ \\
\hline EU (mean) & $6,6 \%$ & $4,6 \%$ & $10,7 \%$ \\
\hline
\end{tabular}

Note: welfare gains are relative to the counterfactual scenario, in which the EU is replaced by a standard RTA. Welfare gains computed from equation (5). * weighted by share in consumption. 
trade elasticity interpretation is radically different. EU-related trade costs cuts are assumed identical, but the consumer now sees foreign and domestic goods as less substitutable. The distorsion imposed by trade costs is more damaging if substitution away from expensive varieties is difficult. A same drop in the AVE thus yields more gains everything else equal. Column (1) in Table 8 reports our benchmark results, while columns (2) and (3) report the welfare effects using the two versions associated with PPML PTI effects. It is interesting to note that the benchmark welfare effects using OLS gravity results are bracketed by the two versions of the PPML welfare calculations. Overall, the average effect of the EU on welfare on member states is bounded between $3 \%$ and $7 \%$.

\subsection{Unilateral exits}

So far, we have assumed as a counterfactual scenario a world without the European Union, replaced by WTO rules or a standard RTA between EU members. In this sub-section, we investigate the welfare gains of European integration under a different counterfactual where the $\mathrm{EU}$ is still in place between other members and each country taken in isolation does not participate.

Table 10 focuses on the RTA scenario with intermediate goods (i.e. column (1) of table 8) and compares benchmark results (column 1) with a scenario under which the exit is unilateral in column (2). Compared to the benchmark scenario, the trade impact is ambiguous since such single country non-membership would have two opposite impacts through the multilateral resistance adjustment and the GDP adjustment in equation (7). By restricting the access to EU markets only to one outside country, the trade impact should be larger because multilateral resistance would drop less in EU markets, whereas the GDP adjustment would go in the opposite direction and reduce less the trade impact in this alternative counterfactual compared to the benchmark. Overall, the losses from unilateral exits seem marginally larger than the losses from complete EU elimination, specially for small countries.

\section{How does Brexit affect the gains from EU?}

In this section, we consider how Brexit will affect the gains from European integration for the remaining EU members. We re-run the counterfactual exercise conducted in section 4.2 assuming that the exit of the UK from the EU has already happened, and compare the welfare gains under the two scenarios. More precisely, we assume a similar scenario in the post-Brexit case as the one prevailing in the counterfactual considered in our main exercise. 
Table 10 - Welfare gains from EU under different scenarios

\begin{tabular}{|c|c|c|}
\hline $\begin{array}{l}\text { Counterfactual } \\
\text { Assumption }\end{array}$ & $\begin{array}{c}(1) \\
\text { to RTA } \\
\text { with inte } \\
\text { baseline }\end{array}$ & $\begin{array}{c}(2) \\
\text { to RTA } \\
\text { rmediates } \\
\text { Unilateral } \\
\text { Exit }\end{array}$ \\
\hline AUT & $7,7 \%$ & $8,2 \%$ \\
\hline BEL & $8,5 \%$ & $9,1 \%$ \\
\hline BGR & $6,7 \%$ & $7,0 \%$ \\
\hline CYP & $3,5 \%$ & $3,7 \%$ \\
\hline CZE & $10,8 \%$ & $11,4 \%$ \\
\hline DEU & $4,5 \%$ & $4,9 \%$ \\
\hline DNK & $5,6 \%$ & $5,9 \%$ \\
\hline ESP & $3,2 \%$ & $3,3 \%$ \\
\hline EST & $10,4 \%$ & $11,1 \%$ \\
\hline FIN & $4,1 \%$ & $4,4 \%$ \\
\hline FRA & $3,4 \%$ & $3,6 \%$ \\
\hline GBR & $2,3 \%$ & $2,4 \%$ \\
\hline GRC & $2,4 \%$ & $2,6 \%$ \\
\hline HRV & $6,1 \%$ & $6,5 \%$ \\
\hline HUN & $14,2 \%$ & $15,2 \%$ \\
\hline IRL & $6,8 \%$ & $7,0 \%$ \\
\hline ITA & $2,8 \%$ & $2,9 \%$ \\
\hline LTU & $8,7 \%$ & $9,2 \%$ \\
\hline LUX & $8,2 \%$ & $8,7 \%$ \\
\hline LVA & $6,4 \%$ & $6,9 \%$ \\
\hline MLT & $8,2 \%$ & $8,6 \%$ \\
\hline NLD & $7,6 \%$ & $8,0 \%$ \\
\hline POL & $6,0 \%$ & $6,4 \%$ \\
\hline PRT & $5,2 \%$ & $5,5 \%$ \\
\hline ROU & $4,6 \%$ & $4,9 \%$ \\
\hline SVK & $12,0 \%$ & $12,9 \%$ \\
\hline SVN & $10,5 \%$ & $11,2 \%$ \\
\hline SWE & $4,8 \%$ & $5,0 \%$ \\
\hline EU (weighted mean) & $4,4 \%$ & $4,7 \%$ \\
\hline EU (mean) & $6,6 \%$ & $7,0 \%$ \\
\hline
\end{tabular}

Note: welfare gains are relative to the counterfactual scenario, in which the EU is either replaced by a standard RTA. Welfare gains computed from equation (5). * weighted by share in consumption. 
Such an exercise is especially interesting in the context of the domino's theory of the spread of RTAs put forward by Baldwin (1993) and Baldwin and Jaimovich (2012), which implies that changes in the gains from regional integration are likely to affect the political balance regarding trade integration in member countries.

\subsection{Brexit}

We first present the results of the Brexit counterfactual on its own. As in the baseline analysis, we consider the impact of the exit of the United Kingdom from the European Union under alternative scenarios for the post-Brexit EU-UK trade relationship - trade between the UK and the EU is governed by either a "standard" RTA or by WTO rules -, and under different modeling assumptions - with intermediate goods (equation 5) or without (equation 6). The resulting trade matrix under each case is used as an input in the corresponding counterfactual.

The results presented in Table 11 show substantial welfare losses for the UK in the range of $-0.8 \%$ to $-2.9 \%$ of GDP (first row of the table) depending on the scenario and modeling assumptions. Considering intermediate goods magnifies the losses from reduced trade openness, by a factor of about 3 . While the losses are larger in a post-Brexit governed by WTO rules only, it is interesting to note that around $80 \%$ of the losses come from leaving the single market $(0.8 / 1.0$ and $2.4 / 2.9)$, i.e. are not related to the re-installation of tariffs barriers which remain at zero in the scenario of a standard RTA arrangement.

Brexit also imposes losses to other members of the European Union, but these are generally one order of magnitude lower than for the UK. GDP decreases by $0.2 \%$ to $0.6 \%$ for the average EU country. With its close geographic and historical linkages with the UK, Ireland stands as an exception with losses comparable to UK ones.

\subsection{Brexit: signing with third countries}

We now want to illustrate the specificities of European integration by investigating to which extent the UK could compensate the losses from leaving the single market by signing RTAs with third countries (a possibility that has been put forward forcefully by Brexit proponents). Specifically, we compute the welfare gains from implementing an RTA with the United States, Canada, and Australia (all three) after Brexit, and contrast the magnitude with the losses from exiting the EU computed in the above section.

Table 12 shows that the UK would benefit from signing trade agreements with large English-speaking third countries. Those would however not offset the loss of EU 
Table 11 - Welfare losses from Brexit under different scenarios

\begin{tabular}{lcccc}
\hline \hline & $(1)$ & $(2)$ & $(3)$ & $(4)$ \\
Counterfactual & to RTA & to MFN & to RTA & to MFN \\
Assumption & with intermediates & without intermediates \\
\hline GBR & $-2,4 \%$ & $-2,9 \%$ & $-0,8 \%$ & $-1,0 \%$ \\
AUT & $-0,1 \%$ & $-0,1 \%$ & $0,0 \%$ & $0,0 \%$ \\
BEL & $-0,6 \%$ & $-0,8 \%$ & $-0,2 \%$ & $-0,3 \%$ \\
BGR & $-0,1 \%$ & $-0,2 \%$ & $-0,1 \%$ & $-0,1 \%$ \\
CYP & $-0,4 \%$ & $-0,5 \%$ & $-0,2 \%$ & $-0,2 \%$ \\
CZE & $-0,3 \%$ & $-0,3 \%$ & $-0,1 \%$ & $-0,1 \%$ \\
DEU & $-0,3 \%$ & $-0,4 \%$ & $-0,1 \%$ & $-0,1 \%$ \\
DNK & $-0,4 \%$ & $-0,5 \%$ & $-0,2 \%$ & $-0,2 \%$ \\
ESP & $-0,2 \%$ & $-0,3 \%$ & $-0,1 \%$ & $-0,1 \%$ \\
EST & $-0,2 \%$ & $-0,3 \%$ & $-0,1 \%$ & $-0,1 \%$ \\
FIN & $-0,2 \%$ & $-0,2 \%$ & $-0,1 \%$ & $-0,1 \%$ \\
FRA & $-0,3 \%$ & $-0,3 \%$ & $-0,1 \%$ & $-0,1 \%$ \\
GRC & $-0,1 \%$ & $-0,2 \%$ & $0,0 \%$ & $-0,1 \%$ \\
HRV & $-0,1 \%$ & $-0,1 \%$ & $0,0 \%$ & $0,0 \%$ \\
HUN & $-0,3 \%$ & $-0,4 \%$ & $-0,1 \%$ & $-0,1 \%$ \\
IRL & $-2,6 \%$ & $-3,2 \%$ & $-1,0 \%$ & $-1,2 \%$ \\
ITA & $-0,2 \%$ & $-0,2 \%$ & $-0,1 \%$ & $-0,1 \%$ \\
LTU & $-0,4 \%$ & $-0,5 \%$ & $-0,1 \%$ & $-0,2 \%$ \\
LUX & $-1,5 \%$ & $-1,9 \%$ & $-0,8 \%$ & $-1,0 \%$ \\
LVA & $-0,2 \%$ & $-0,3 \%$ & $-0,1 \%$ & $-0,1 \%$ \\
MLT & $-1,5 \%$ & $-1,9 \%$ & $-0,8 \%$ & $-1,0 \%$ \\
NLD & $-0,6 \%$ & $-0,8 \%$ & $-0,2 \%$ & $-0,3 \%$ \\
POL & $-0,3 \%$ & $-0,3 \%$ & $-0,1 \%$ & $-0,1 \%$ \\
PRT & $-0,2 \%$ & $-0,3 \%$ & $-0,1 \%$ & $-0,1 \%$ \\
ROU & $-0,1 \%$ & $-0,1 \%$ & $0,0 \%$ & $-0,1 \%$ \\
SVK & $-0,3 \%$ & $-0,3 \%$ & $-0,1 \%$ & $-0,1 \%$ \\
SVN & $-0,1 \%$ & $-0,2 \%$ & $0,0 \%$ & $-0,1 \%$ \\
SWE & $-0,3 \%$ & $-0,4 \%$ & $-0,1 \%$ & $-0,2 \%$ \\
EU (mean) & $-0,4 \%$ & $-0,5 \%$ & $-0,2 \%$ & $-0,2 \%$ \\
\hline \hline
\end{tabular}

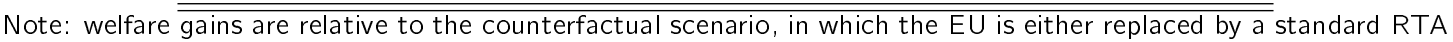
(columns (1) and (3)) or WTO rules (columns (2) and (4)). Welfare gains computed from equation (5) in columns (1)-(2) and equation (6) in columns (3)-(4). 
market access for at least two reasons. First, the rules of gravity in international trade make EU countries natural trade partners for the UK; by their geographic location, other large countries, even those sharing historical linkages with the UK, cannot replace the closest partners from continental Europe. After Brexit, 26\% (in the WTO scenario) to 33\% (in the RTA scenario) of British imports of goods and services would still originate from the EU, down from 53\% before. Second, trade agreements with other countries cannot match the depth of integration provided by the European Single market, that goes well beyond regular trade agreements tariff reductions by addressing behind-the-border trade impediments. Overall, signing RTAs with all three countries would increase the UK GDP by $0.48 \%(0.17 \%$ when assuming no intermediate goods), offsetting around a fifth of the losses from Brexit. Each of these four countries would gain little: gains from Canada for instance are $0.12 \%$ of GDP under the best scenario of signing an RTA with the UK. Finally, Ireland would be the EU country suffering the most from the trade diversion effects of the new RTAs signed by the UK, with a cumulated maximum loss of $-0.01 \%$ of GDP.

Table 12 - Welfare gains from alternative RTAs

\begin{tabular}{lcccc}
\hline \hline Counterfactual & $\begin{array}{c}(1) \\
\text { To RTA } \\
\text { with intermediate }\end{array}$ & $\begin{array}{c}(2) \\
\text { To MFN }\end{array}$ & $\begin{array}{c}(3) \\
\text { To RTA } \\
\text { without intermediate }\end{array}$ \\
\hline GBR & & & & $\begin{array}{c}(4) \\
\text { To MFN }\end{array}$ \\
AUS & $0,48 \%$ & $0,48 \%$ & $0,17 \%$ & $0,17 \%$ \\
CAN & $0,05 \%$ & $0,05 \%$ & $0,02 \%$ & $0,02 \%$ \\
USA & $0,12 \%$ & $0,12 \%$ & $0,04 \%$ & $0,04 \%$ \\
IRL & $0,06 \%$ & $0,06 \%$ & $0,02 \%$ & $0,02 \%$ \\
\hline
\end{tabular}

Note: welfare gains are relative to the counterfactual scenario, in which theUK- EU trade relationships are either governed by a standard RTA (columns (1) and (3)) or WTO rules (columns (2) and (4)). Welfare gains computed from equation (5) in columns (1)-(2) and equation (6) in columns (3)-(4).

\subsection{Gains from the EU following Brexit}

Table 13 presents the gains that members obtain from belonging to the EU taking Brexit into account. Gains remain substantial on average. Comparing to Table 8, it however shows that the exit of the UK from the European Union reduces the gains from EU integration for the remaining members. While on average the foregone gains are small, they can be substantial for specific countries that have special linkages with the British economy. The average reduction in the welfare 
gains from EU stands at $0.5 \%$ on a non-weighted basis, which represents a small part of the overall estimated gains from trade integration today (estimated between $2 \%$ and $8 \%$ in our baseline analysis, see Table 9). An exception is Ireland which is particularly exposed to the exit of its main economic partner, with a reduction of the gains from EU integration by close to $40 \%$ e.g. from $6.8 \%$ to $4.1 \%$ in the RTA scenario with intermediates. Malta and Cyprus also experience a substantial reduction in the gains they derive from the EU after Brexit.

\section{Conclusion}

We provide in this paper quantified evidence regarding different scenarios of a deconstruction of the European Union. Those can naturally also be interpreted as what the EU brought in terms of welfare to the population of member countries. The costs of Non-Europe (weighted by country size) are estimated to vary between $3 \%$ and $7 \%$ on average for the EU depending on the counterfactual ("normal" RTA vs return to WTO rules notably). There is wide variation across member countries, with costs reacting strongly to size and initial openness ratio of the separating countries: small open economies in Europe gain the most, particularly the Eastern part of the continent. We also consider unilateral exits which systematically exhibit larger losses. Last, we quantify the domino effects linked to Brexit. The gains from EU trade integration are smaller if/when the United Kingdom already left the Union. We also quantify the compensation that the UK would obtain in terms of welfare with signing agreements with "new" partners such as the United States, Canada, Australia. The welfare gains are positive but an order of magnitude smaller than the losses incurred from Brexit.

One of the major inputs of our calculations is a gravity estimation of the direct impact of EU integration on trade patterns. This econometric step estimates in particular different aspects of European integration, like the single market and the Schengen agreement. We point to strong effects-rising over time-consistently across different estimation methods. The large estimated trade effect of the EU is the major explanation for our conclusion that a dismantling of the EU (partial or complete) would have important negative effects on welfare. Why are those gravity estimates large? One aspect that the ex-post gravity approach is able to capture through large EU coefficients is the multidimensional nature of the European integration process. Note first that EU provisions regarding barriers to trade in goods are much deeper than usual RTA tariff removal. The handling of norms is particularly telling: the mutual recognition principle going far beyond regular product standard harmonization in reducing the cost of meeting norms requirements on 
Table 13 - Welfare gains from EU after Brexit

\begin{tabular}{|c|c|c|c|}
\hline $\begin{array}{l}\text { Counterfactual } \\
\text { Assumption }\end{array}$ & $\begin{array}{l}\quad(1) \\
\text { to RTA } \\
\text { with inter } \\
\text { baseline }\end{array}$ & $\begin{array}{c}(2) \\
\text { to RTA } \\
\text { mediates } \\
\text { Brexit }\end{array}$ & $\begin{array}{c}(3) \\
\text { Difference } \\
(2)-(1)\end{array}$ \\
\hline AUT & $7,7 \%$ & $7,6 \%$ & $0,1 \%$ \\
\hline BEL & $8,5 \%$ & $7,8 \%$ & $0,6 \%$ \\
\hline BGR & $6,7 \%$ & $6,5 \%$ & $0,2 \%$ \\
\hline CYP & $3,5 \%$ & $3,1 \%$ & $0,4 \%$ \\
\hline CZE & $10,6 \%$ & $10,4 \%$ & $0,3 \%$ \\
\hline DEU & $4,5 \%$ & $4,3 \%$ & $0,3 \%$ \\
\hline DNK & $5,6 \%$ & $5,2 \%$ & $0,5 \%$ \\
\hline ESP & $3,2 \%$ & $3,0 \%$ & $0,2 \%$ \\
\hline EST & $10,4 \%$ & $10,3 \%$ & $0,2 \%$ \\
\hline FIN & $4,1 \%$ & $3,8 \%$ & $0,3 \%$ \\
\hline FRA & $3,4 \%$ & $3,1 \%$ & $0,3 \%$ \\
\hline GRC & $2,4 \%$ & $2,3 \%$ & $0,1 \%$ \\
\hline HRV & $6,1 \%$ & $6,0 \%$ & $0,1 \%$ \\
\hline HUN & $14,2 \%$ & $13,8 \%$ & $0,4 \%$ \\
\hline IRL & $6,8 \%$ & $4,1 \%$ & $2,7 \%$ \\
\hline ITA & $2,8 \%$ & $2,6 \%$ & $0,2 \%$ \\
\hline LTU & $8,7 \%$ & $8,2 \%$ & $0,5 \%$ \\
\hline LUX & $8,2 \%$ & $6,6 \%$ & $1,6 \%$ \\
\hline LVA & $6,3 \%$ & $6,2 \%$ & $0,1 \%$ \\
\hline MLT & $8,2 \%$ & $6,6 \%$ & $1,6 \%$ \\
\hline NLD & $7,4 \%$ & $6,9 \%$ & $0,5 \%$ \\
\hline POL & $6,0 \%$ & $5,7 \%$ & $0,3 \%$ \\
\hline PRT & $5,1 \%$ & $5,0 \%$ & $0,1 \%$ \\
\hline ROU & $4,5 \%$ & $4,4 \%$ & $0,1 \%$ \\
\hline SVK & $12,0 \%$ & $11,7 \%$ & $0,3 \%$ \\
\hline SVN & $10,5 \%$ & $10,4 \%$ & $0,1 \%$ \\
\hline SWE & $4,8 \%$ & $4,5 \%$ & $0,3 \%$ \\
\hline EU (mean) & $6,8 \%$ & $6,3 \%$ & $0,5 \%$ \\
\hline
\end{tabular}

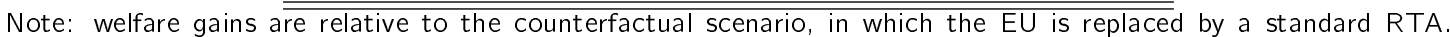
Welfare gains computed from equation (5). 
destination markets. Moreover the umbrella of the European Court of Justice guarantees the current and future mutual recognition of norms and standards, reducing policy uncertainty (Handley and Limão, 2017). But other dimensions of the Single Market, not directly related to trade in goods, are likely to favor further trade integration between EU members. The four freedoms guaranteed by the Single Market allow for the free movement of goods, services, capital and labor, which are likely to complement each other in complex ways. For instance, the liberalization of trade in service is likely to increase trade in goods since selling complementary services increases the profitability of manufacturing exporters (Ariu et al., 2017). In turn, the free movement of labor facilitates the provision of services abroad through mobility of employees or commercial presence through subsidiaries, potentially boosting exports of goods or services (Krautheim, 2013). Other illustrations for service trade regard exports of financial services which typically require flows of data and so agreements on data privacy, or licensing that require strong intellectual property right protection. Such complementarities are implicitly contained in estimates of the trade impact of the Single market using the gravity framework. Identifying those complementarities separately seems interesting avenue for future research.

A caveat to our results is that we restrain our exercise to comparative statics longrun effects (once the estimated partial effects on trade have fully taken place), with no ambition of looking at what happens in the short run. Also there is no dynamic mechanism that would operate through a growth-promoting effect of trade in our analysis, and we keep our sectoral dimension quite rough in the simulation part of the paper, in order to match with the econometric part, which sacrifices sectoral detail for time coverage of the analysis. Other effects of EU disintegration might be channeled through lower migration and capital flows. The literature strongly suggests all those omitted dimensions to increase welfare gains from trade integration.

\section{References}

Aghion, P., Harris, C., and Vickers, J. (1997). Competition and growth with stepby-step innovation: An example. European Economic Review, 41(3-5):771-782.

Aghion, P. and Howitt, P. (1992). A Model of Growth through Creative Destruction. Econometrica, 60(2):323-351.

Ariu, A., Mayneris, F., and Parenti, M. (2017). Providing Services to Boost Goods Exports: Theory and Evidence. mimeo. 
Arkolakis, C., Costinot, A., and Rodriguez-Clare, A. (2012). New trade models, same old gains? American Economic Review, 102(1):94-130.

Autor, D., Dorn, D., Hanson, G. H., Pisano, G., and Shu, P. (2016). Foreign Competition and Domestic Innovation: Evidence from U.S. Patents. NBER Working Papers 22879, National Bureau of Economic Research, Inc.

Baier, S. L. and Bergstrand, J. H. (2007). Do free trade agreements actually increase members' international trade? Journal of international Economics, 71(1):72-95.

Baier, S. L., Bergstrand, J. H., Egger, P., and McLaughlin, P. A. (2008). Do economic integration agreements actually work? issues in understanding the causes and consequences of the growth of regionalism. The World Economy, 31(4):461-497.

Baier, S. L., Bergstrand, J. H., and Feng, M. (2014). Economic integration agreements and the margins of international trade. Journal of International Economics, 93(2):339-350.

Baldwin, R. (1993). A Domino Theory of Regionalism. CEPR Discussion Papers 857, C.E.P.R. Discussion Papers.

Baldwin, R. (2006). The euro's trade effects. Technical report, European Central Bank.

Baldwin, R. and Jaimovich, D. (2012). Are Free Trade Agreements contagious? Journal of International Economics, 88(1):1-16.

Baldwin, R. E. and Venables, A. J. (1995). Regional economic integration. Handbook of international economics, 3:1597-1644.

Bas, M., Mayer, T., and Thoenig, M. (2017). From micro to macro: demand, supply, and heterogeneity in the trade elasticity. Journal of International Economics, 108:1-19.

Bergstrand, J. H., Larch, M., and Yotov, Y. V. (2015). Economic integration agreements, border effects, and distance elasticities in the gravity equation. European Economic Review, 78:307-327.

Bernard, A., Eaton, J., Jensen, J., and Kortum, S. (2003). Plants and productivity in international trade. American Economic Review, 93(4):1268-1290.

Bloom, N., Draca, M., and Reenen, J. V. (2016). Trade Induced Technical Change? The Impact of Chinese Imports on Innovation, IT and Productivity. Review of Economic Studies, 83(1):87-117.

Carrere, C. (2006). Revisiting the effects of regional trade agreements on trade flows with proper specification of the gravity model. European Economic Review, 50(2):223-247. 
Checchini, P., Catina, M., and Jacquemin, A. (1988). The Benefits of a Single Market.

Cheng, I.-H. and Wall, H. J. (2005). Controlling for heterogeneity in gravity models of trade and integration. Review, (Jan):49-63.

Costinot, A. and Rodriguez-Clare, A. (2014). Trade theory with numbers: Quantifying the consequences of globalization. In Helpman, E., editor, Handbook of international economics, volume 4. Elsevier.

Dekle, R., Eaton, J., and Kortum, S. (2007). Unbalanced trade. American Economic Review, 97(2):351-355.

Dhingra, S., Huang, H., Ottaviano, G., Pessoa, J. P., Sampson, T., and Reenen, J. V. (2016). The Costs and Benefits of Leaving the EU: Trade Effects. Cep discussion paper.

Eaton, J. and Kortum, S. (2001). Trade in capital goods. European Economic Review, 45(7):1195-1235.

Eaton, J., Kortum, S., and Sotelo, S. (2013). International trade: Linking micro and macro. In Acemoglu, D., Arellano, M., and Dekel, E., editors, Advances in Economics and Econometrics Tenth World Congres, volume II: Applied Economics. Cambridge University Press.

Eicher, T. S. and Henn, C. (2011). In search of wto trade effects: Preferential trade agreements promote trade strongly, but unevenly. Journal of International Economics, 83(2):137-153.

Fontagné, L., Freudenberg, M., and Péridy, N. (1998). Intra-Industry Trade and the Single Market: Quality Matters. CEPR Discussion Papers 1959, C.E.P.R. Discussion Papers.

Handley, K. and Limão, N. (2017). Policy Uncertainty, Trade, and Welfare: Theory and Evidence for China and the United States. American Economic Review, 107(9):2731-2783.

Head, K. and Mayer, T. (2014). Gravity equations: Workhorse,toolkit, and cookbook. In Gopinath, G., Helpman, E., and Rogoff, K., editors, Handbook of international economics, volume 4, pages 131-196. Elsevier.

Head, K., Mayer, T., and Ries, J. (2009). How remote is the offshoring threat? European Economic Review, 53(4):429-444.

Head, K., Mayer, T., and Ries, J. (2010). The erosion of colonial trade linkages after independence. Journal of International Economics, 81(1):1-14.

Helpman, E., Melitz, M., and Rubinstein, Y. (2008). Estimating trade flows: Trading partners and trading volumes. Quarterly Journal of Economics, 123(2):441487. 
Krautheim, S. (2013). Export-supporting FDI. Canadian Journal of Economics, 46(4):1571-1605.

Larch, M., Wanner, J., Yotov, Y., and Zylkin, T. (2017). The currency union effect: A ppml re-assessment with high-dimensional fixed effects. Working Paper 2017-07, Drexel University.

Limão, N. (2016). Preferential trade agreements. In Bagwell, K. and Staiger, R. W., editors, Handbook of Commercial Policy, volume 1B, pages 281-367. Elsevier.

Martin, P., Mayer, T., and Thoenig, M. (2012). The Geography of Conflicts and Regional Trade Agreements. American Economic Journal: Macroeconomics, 4(4):1-35.

Novy, D. (2013). International trade without ces: Estimating translog gravity. Journal of International Economics, 89:271-282.

Santos Silva, J. and Tenreyro, S. (2006). The log of gravity. The Review of Economics and Statistics, 88(4):641-658.

Santos Silva, J. and Tenreyro, S. (2010). Currency unions in prospect and retrospect. Annu. Rev. Econ, 2:51-74.

Spolaore, E., Alesina, A., and Wacziarg, R. (2000). Economic Integration and Political Disintegration. American Economic Review, 90(5):1276-1296.

Timmer, M. P., Dietzenbacher, E., Los, B., Stehrer, R., and Vries, G. J. (2015). An illustrated user guide to the world input-output database: the case of global automotive production. Review of International Economics, 23(3):575-605.

Tinbergen, J. (1962). Shaping the World Economy: Suggestions for an International Economic Policy. Twentieth Century Fund, New-York.

Vicard, V. (2012). Trade, conflict, and political integration: Explaining the heterogeneity of regional trade agreements. European Economic Review, 56(1):54-71.

World Trade Organization (2011). World Trade Report 2011: The WTO and preferential trade agreements: From co-existence to coherence. 


\section{Appendix}

\section{Appendix}

A. Time varying partial trade impact of the EU

Table A.1 - The effect of European integration on trade over time: detailed results

\begin{tabular}{|c|c|c|c|c|}
\hline Estimator & $\begin{array}{l}(1) \\
\text { OLS }\end{array}$ & $\begin{array}{l}(2) \\
\text { OLS }\end{array}$ & $\begin{array}{c}(3) \\
\text { PPML }\end{array}$ & $\begin{array}{c}(4) \\
\text { PPML }\end{array}$ \\
\hline Both GATT dum. & $\begin{array}{c}0.135^{a} \\
(0.027)\end{array}$ & $\begin{array}{c}0.133^{a} \\
(0.027)\end{array}$ & $\begin{array}{c}-0.080 \\
(0.074)\end{array}$ & $\begin{array}{c}-0.084 \\
(0.075)\end{array}$ \\
\hline Shared currency dum. & $\begin{array}{c}0.339^{a} \\
(0.068)\end{array}$ & $\begin{array}{c}0.340^{a} \\
(0.068)\end{array}$ & $\begin{array}{c}0.828^{a} \\
(0.126)\end{array}$ & $\begin{array}{l}0.838^{a} \\
(0.127)\end{array}$ \\
\hline Euro area dum. & $\begin{array}{l}-0.262^{a} \\
(0.060)\end{array}$ & $\begin{array}{l}-0.187^{a} \\
(0.063)\end{array}$ & $\begin{array}{l}-0.105^{b} \\
(0.043)\end{array}$ & $\begin{array}{l}-0.027 \\
(0.041)\end{array}$ \\
\hline RTA dum. & $\begin{array}{c}0.391^{a} \\
(0.024)\end{array}$ & $\begin{array}{c}0.391^{a} \\
(0.024)\end{array}$ & $\begin{array}{c}0.058 \\
(0.046)\end{array}$ & $\begin{array}{c}0.054 \\
(0.046)\end{array}$ \\
\hline EU dum. 1958 & $\begin{array}{l}-0.038 \\
(0.088)\end{array}$ & $\begin{array}{l}-0.060 \\
(0.091)\end{array}$ & $\begin{array}{c}-0.102 \\
(0.123)\end{array}$ & $\begin{array}{l}-0.085 \\
(0.131)\end{array}$ \\
\hline EU dum. 1959 & $\begin{array}{c}0.118 \\
(0.083)\end{array}$ & $\begin{array}{c}0.096 \\
(0.087)\end{array}$ & $\begin{array}{c}0.001 \\
(0.110)\end{array}$ & $\begin{array}{c}0.018 \\
(0.117)\end{array}$ \\
\hline EU dum. 1960 & $\begin{array}{c}0.178^{b} \\
(0.082)\end{array}$ & $\begin{array}{l}0.156^{c} \\
(0.087)\end{array}$ & $\begin{array}{c}0.027 \\
(0.100)\end{array}$ & $\begin{array}{c}0.044 \\
(0.108)\end{array}$ \\
\hline EU dum. 1961 & $\begin{array}{c}0.281^{a} \\
(0.083)\end{array}$ & $\begin{array}{c}0.258^{a} \\
(0.088)\end{array}$ & $\begin{array}{c}0.123 \\
(0.098)\end{array}$ & $\begin{array}{c}0.139 \\
(0.106)\end{array}$ \\
\hline EU dum. 1962 & $\begin{array}{l}0.335^{a} \\
(0.083)\end{array}$ & $\begin{array}{c}0.312^{a} \\
(0.088)\end{array}$ & $\begin{array}{c}0.212^{b} \\
(0.092)\end{array}$ & $\begin{array}{l}0.227^{b} \\
(0.099)\end{array}$ \\
\hline EU dum. 1963 & $\begin{array}{c}0.350^{a} \\
(0.082)\end{array}$ & $\begin{array}{c}0.326^{a} \\
(0.088)\end{array}$ & $\begin{array}{c}0.299^{a} \\
(0.088)\end{array}$ & $\begin{array}{l}0.314^{a} \\
(0.096)\end{array}$ \\
\hline EU dum. 1964 & $\begin{array}{c}0.496^{a} \\
(0.079)\end{array}$ & $\begin{array}{c}0.472^{a} \\
(0.086)\end{array}$ & $\begin{array}{c}0.373^{a} \\
(0.083)\end{array}$ & $\begin{array}{l}0.387^{a} \\
(0.091)\end{array}$ \\
\hline EU dum. 1965 & $\begin{array}{c}0.428^{a} \\
(0.078)\end{array}$ & $\begin{array}{c}0.404^{a} \\
(0.085)\end{array}$ & $\begin{array}{c}0.398^{a} \\
(0.081)\end{array}$ & $\begin{array}{l}0.412^{a} \\
(0.089)\end{array}$ \\
\hline EU dum. 1966 & $\begin{array}{c}0.444^{a} \\
(0.081)\end{array}$ & $\begin{array}{c}0.419^{a} \\
(0.088)\end{array}$ & $\begin{array}{c}0.434^{a} \\
(0.077)\end{array}$ & $\begin{array}{l}0.446^{a} \\
(0.084)\end{array}$ \\
\hline EU dum. 1967 & $0.469^{a}$ & $0.444^{a}$ & $0.460^{a}$ & $0.471^{a}$ \\
\hline
\end{tabular}




\begin{tabular}{|c|c|c|c|c|}
\hline \multicolumn{5}{|c|}{ Continued from previous page } \\
\hline & $(0.074)$ & $(0.083)$ & $(0.073)$ & $(0.081)$ \\
\hline \multirow[t]{2}{*}{ EU dum. } & $0.467^{a}$ & $0.442^{a}$ & $0.567^{a}$ & $0.575^{a}$ \\
\hline & $(0.075)$ & $(0.084)$ & $(0.074)$ & $(0.081)$ \\
\hline \multirow[t]{2}{*}{ EU dum. } & $0.418^{a}$ & $0.393^{a}$ & $0.646^{a}$ & $0.655^{a}$ \\
\hline & $(0.079)$ & $(0.088)$ & $(0.070)$ & $(0.076)$ \\
\hline \multirow[t]{2}{*}{ EU dum. } & $0.457^{a}$ & $0.432^{a}$ & $0.705^{a}$ & $0.711^{a}$ \\
\hline & $(0.074)$ & $(0.083)$ & $(0.074)$ & $(0.078)$ \\
\hline \multirow[t]{2}{*}{ EU dum. } & $0.514^{a}$ & $0.489^{a}$ & $0.763^{a}$ & $0.768^{a}$ \\
\hline & $(0.071)$ & $(0.080)$ & $(0.074)$ & $(0.077)$ \\
\hline \multirow[t]{2}{*}{ EU dum. } & $0.613^{a}$ & $0.587^{a}$ & $0.775^{a}$ & $0.780^{a}$ \\
\hline & $(0.070)$ & $(0.078)$ & $(0.068)$ & $(0.071)$ \\
\hline \multirow{2}{*}{ EU dum. 1973} & $0.313^{a}$ & $0.584^{a}$ & $0.382^{a}$ & $0.650^{a}$ \\
\hline & $(0.065)$ & $(0.079)$ & $(0.091)$ & $(0.079)$ \\
\hline \multirow[t]{2}{*}{ EU dum. 1974} & $0.180^{a}$ & $0.411^{a}$ & $0.308^{a}$ & $0.509^{a}$ \\
\hline & $(0.065)$ & $(0.084)$ & $(0.092)$ & $(0.086)$ \\
\hline \multirow[t]{2}{*}{ EU dum. 1975} & $0.190^{a}$ & $0.381^{a}$ & $0.411^{a}$ & $0.588^{a}$ \\
\hline & $(0.066)$ & $(0.080)$ & $(0.088)$ & $(0.082)$ \\
\hline \multirow[t]{2}{*}{ EU dum. 1976} & $0.214^{a}$ & $0.394^{a}$ & $0.465^{a}$ & $0.619^{a}$ \\
\hline & $(0.062)$ & $(0.084)$ & $(0.084)$ & $(0.079)$ \\
\hline \multirow[t]{2}{*}{ EU dum. 1977} & $0.194^{a}$ & $0.313^{a}$ & $0.475^{a}$ & $0.590^{a}$ \\
\hline & $(0.063)$ & $(0.082)$ & $(0.081)$ & $(0.080)$ \\
\hline \multirow[t]{2}{*}{ EU dum. 1978} & $0.202^{a}$ & $0.327^{a}$ & $0.496^{a}$ & $0.600^{a}$ \\
\hline & $(0.063)$ & $(0.086)$ & $(0.081)$ & $(0.079)$ \\
\hline \multirow[t]{2}{*}{ EU dum. 1979} & $0.214^{a}$ & $0.293^{a}$ & $0.537^{a}$ & $0.608^{a}$ \\
\hline & $(0.062)$ & $(0.083)$ & $(0.077)$ & $(0.077)$ \\
\hline \multirow[t]{2}{*}{ EU dum. 1980} & $0.201^{a}$ & $0.260^{a}$ & $0.548^{a}$ & $0.594^{a}$ \\
\hline & $(0.060)$ & $(0.077)$ & $(0.080)$ & $(0.080)$ \\
\hline \multirow[t]{2}{*}{ EU dum. 1981} & $0.291^{a}$ & $0.229^{a}$ & $0.523^{a}$ & $0.554^{a}$ \\
\hline & $(0.062)$ & $(0.078)$ & $(0.079)$ & $(0.081)$ \\
\hline \multirow[t]{2}{*}{ EU dum. 1982} & $0.372^{a}$ & $0.202^{a}$ & $0.546^{a}$ & $0.555^{a}$ \\
\hline & $(0.063)$ & $(0.075)$ & $(0.072)$ & $(0.073)$ \\
\hline \multirow[t]{2}{*}{ EU dum. 1983} & $0.396^{a}$ & $0.283^{a}$ & $0.589^{a}$ & $0.538^{a}$ \\
\hline & $(0.065)$ & $(0.077)$ & $(0.070)$ & $(0.068)$ \\
\hline \multirow[t]{2}{*}{ EU dum. 1984} & $0.365^{a}$ & $0.267^{a}$ & $0.577^{a}$ & $0.524^{a}$ \\
\hline & $(0.063)$ & $(0.076)$ & $(0.070)$ & $(0.068)$ \\
\hline \multirow[t]{2}{*}{ EU dum. 1985} & $0.400^{a}$ & $0.309^{a}$ & $0.578^{a}$ & $0.526^{a}$ \\
\hline & $(0.062)$ & $(0.075)$ & $(0.071)$ & $(0.068)$ \\
\hline EU dum. 1986 & $0.327^{a}$ & $0.317^{a}$ & $0.574^{a}$ & $0.557^{a}$ \\
\hline
\end{tabular}




\begin{tabular}{|c|c|c|c|c|c|}
\hline \multicolumn{6}{|c|}{ Continued from previous page } \\
\hline & & $(0.058)$ & $(0.072)$ & $(0.069)$ & $(0.066)$ \\
\hline \multirow[t]{2}{*}{ EU dum. } & 1987 & $0.408^{a}$ & $0.363^{a}$ & $0.586^{a}$ & $0.559^{a}$ \\
\hline & & $(0.057)$ & $(0.073)$ & $(0.066)$ & $(0.065)$ \\
\hline \multirow[t]{2}{*}{ EU dum. } & 1988 & $0.409^{a}$ & $0.386^{a}$ & $0.603^{a}$ & $0.573^{a}$ \\
\hline & & $(0.058)$ & $(0.073)$ & $(0.065)$ & $(0.065)$ \\
\hline \multirow[t]{2}{*}{ EU dum. } & 1989 & $0.470^{a}$ & $0.448^{a}$ & $0.590^{a}$ & $0.558^{a}$ \\
\hline & & $(0.060)$ & $(0.074)$ & $(0.061)$ & $(0.063)$ \\
\hline \multirow[t]{2}{*}{ EU dum. } & 1990 & $0.531^{a}$ & $0.439^{a}$ & $0.525^{a}$ & $0.482^{a}$ \\
\hline & & $(0.059)$ & $(0.073)$ & $(0.057)$ & $(0.063)$ \\
\hline \multirow[t]{2}{*}{ EU dum. } & 1991 & $0.549^{a}$ & $0.487^{a}$ & $0.535^{a}$ & $0.494^{a}$ \\
\hline & & $(0.061)$ & $(0.072)$ & $(0.058)$ & $(0.064)$ \\
\hline \multirow[t]{2}{*}{ EU dum. } & 1992 & $0.678^{a}$ & $0.593^{a}$ & $0.550^{a}$ & $0.508^{a}$ \\
\hline & & $(0.060)$ & $(0.071)$ & $(0.056)$ & $(0.063)$ \\
\hline \multirow[t]{2}{*}{ EU dum. } & 1993 & $0.624^{a}$ & $0.526^{a}$ & $0.460^{a}$ & $0.406^{a}$ \\
\hline & & $(0.060)$ & $(0.071)$ & $(0.055)$ & $(0.065)$ \\
\hline \multirow[t]{2}{*}{ EU dum. } & 1994 & $0.589^{a}$ & $0.477^{a}$ & $0.498^{a}$ & $0.446^{a}$ \\
\hline & & $(0.063)$ & $(0.078)$ & $(0.055)$ & $(0.065)$ \\
\hline \multirow[t]{2}{*}{ EU dum. } & 1995 & $0.640^{a}$ & $0.552^{a}$ & $0.571^{a}$ & $0.515^{a}$ \\
\hline & & $(0.054)$ & $(0.078)$ & $(0.055)$ & $(0.072)$ \\
\hline \multirow[t]{2}{*}{ EU dum. } & 1996 & $0.624^{a}$ & $0.534^{a}$ & $0.571^{a}$ & $0.514^{a}$ \\
\hline & & $(0.055)$ & $(0.076)$ & $(0.056)$ & $(0.072)$ \\
\hline \multirow[t]{2}{*}{ EU dum. } & 1997 & $0.669^{a}$ & $0.568^{a}$ & $0.552^{a}$ & $0.493^{a}$ \\
\hline & & $(0.058)$ & $(0.081)$ & $(0.057)$ & $(0.075)$ \\
\hline \multirow[t]{2}{*}{ EU dum. } & 1998 & $0.646^{a}$ & $0.577^{a}$ & $0.549^{a}$ & $0.485^{a}$ \\
\hline & & $(0.055)$ & $(0.077)$ & $(0.057)$ & $(0.076)$ \\
\hline \multirow[t]{2}{*}{ EU dum. } & 1999 & $0.979^{a}$ & $0.796^{a}$ & $0.648^{a}$ & $0.537^{a}$ \\
\hline & & $(0.058)$ & $(0.087)$ & $(0.060)$ & $(0.079)$ \\
\hline \multirow[t]{2}{*}{ EU dum. } & 2000 & $0.994^{a}$ & $0.823^{a}$ & $0.619^{a}$ & $0.511^{a}$ \\
\hline & & $(0.058)$ & $(0.091)$ & $(0.062)$ & $(0.082)$ \\
\hline \multirow[t]{2}{*}{ EU dum. } & 2001 & $0.982^{a}$ & $0.807^{a}$ & $0.590^{a}$ & $0.477^{a}$ \\
\hline & & $(0.060)$ & $(0.095)$ & $(0.065)$ & $(0.085)$ \\
\hline \multirow[t]{2}{*}{ EU dum. } & 2002 & $1.033^{a}$ & $0.849^{a}$ & $0.613^{a}$ & $0.496^{a}$ \\
\hline & & $(0.061)$ & $(0.096)$ & $(0.065)$ & $(0.085)$ \\
\hline \multirow[t]{2}{*}{ EU dum. } & 2003 & $1.106^{a}$ & $0.946^{a}$ & $0.613^{a}$ & $0.499^{a}$ \\
\hline & & $(0.061)$ & $(0.095)$ & $(0.067)$ & $(0.088)$ \\
\hline \multirow[t]{2}{*}{ EU dum. } & 2004 & $1.092^{a}$ & $1.049^{a}$ & $0.677^{a}$ & $0.576^{a}$ \\
\hline & & $(0.054)$ & $(0.097)$ & $(0.071)$ & $(0.088)$ \\
\hline EU dum. & 2005 & $1.130^{a}$ & $1.093^{a}$ & $0.659^{a}$ & $0.532^{a}$ \\
\hline
\end{tabular}




\begin{tabular}{lcccc}
\hline & Continued from previous page & \\
& $(0.055)$ & $(0.091)$ & $(0.070)$ & $(0.086)$ \\
EU dum. 2006 & $1.221^{a}$ & $1.106^{a}$ & $0.712^{a}$ & $0.580^{a}$ \\
& $(0.057)$ & $(0.091)$ & $(0.069)$ & $(0.086)$ \\
EU dum. 2007 & $1.344^{a}$ & $1.112^{a}$ & $0.734^{a}$ & $0.599^{a}$ \\
& $(0.056)$ & $(0.092)$ & $(0.071)$ & $(0.087)$ \\
EU dum. 2008 & $1.399^{a}$ & $1.127^{a}$ & $0.732^{a}$ & $0.592^{a}$ \\
& $(0.063)$ & $(0.093)$ & $(0.072)$ & $(0.086)$ \\
EU dum. 2009 & $1.621^{a}$ & $1.350^{a}$ & $0.750^{a}$ & $0.605^{a}$ \\
& $(0.063)$ & $(0.091)$ & $(0.075)$ & $(0.089)$ \\
EU dum. 2010 & $1.673^{a}$ & $1.416^{a}$ & $0.778^{a}$ & $0.633^{a}$ \\
& $(0.064)$ & $(0.093)$ & $(0.073)$ & $(0.086)$ \\
EU dum. 2011 & $1.664^{a}$ & $1.340^{a}$ & $0.770^{a}$ & $0.624^{a}$ \\
& $(0.066)$ & $(0.095)$ & $(0.072)$ & $(0.085)$ \\
EU dum. 2012 & $1.697^{a}$ & $1.406^{a}$ & $0.777^{a}$ & $0.633^{a}$ \\
& $(0.067)$ & $(0.095)$ & $(0.074)$ & $(0.087)$ \\
Shengen dum. & $-0.099^{b}$ & -0.080 & $-0.057^{c}$ & -0.055 \\
& $(0.044)$ & $(0.054)$ & $(0.030)$ & $(0.035)$ \\
EEA dum. & $1.068^{a}$ & $1.057^{a}$ & $0.429^{a}$ & $0.403^{a}$ \\
& $(0.094)$ & $(0.095)$ & $(0.091)$ & $(0.089)$ \\
EU-Switzerland RTA dum. & $0.853^{a}$ & $0.847^{a}$ & 0.015 & 0.006 \\
& $(0.100)$ & $(0.100)$ & $(0.096)$ & $(0.096)$ \\
EU-Turkey RTA dum. & $-0.235^{c}$ & $-0.236^{c}$ & $0.233^{b}$ & $0.253^{b}$ \\
& $(0.125)$ & $(0.125)$ & $(0.103)$ & $(0.105)$ \\
& $6015)$ &
\end{tabular}

Note: Standard errors clustered for intra-group correlation at the country pair level in parentheses, with significance levels indicated with ${ }^{c}$ for $10 \%,{ }^{b}$ for $5 \%$, ${ }^{a}$ for $1 \%$. All dummy variables for regional agreement membership are "exclusive", i.e. the RTA membership dummy equal zero when EEC or EU is equal to one. Shared currency and euro area dummies are similarly exclusive. All columns include origin $\times$ year, destination $\times$ year and country pair fixed effects. Columns (2) and (4) include year specific dummies for each enlargment (over a 10 year period following the entry) but coefficients are not reported. 


\section{B. Trade effects using PPML estimates of the EU partial trade impact}

Table B.2 - The trade effect of EU integration (RTA scenario with intermediate inputs, PPML estimate of EU PTI)

\begin{tabular}{|c|c|c|c|c|c|c|c|c|c|c|}
\hline \multirow{2}{*}{$\begin{array}{l}\text { Sector } \\
\text { Var. } \\
\text { Origin } \\
\text { State of the world }\end{array}$} & \multicolumn{3}{|c|}{$\begin{array}{c}\text { Goods } \\
\text { Imports } \\
\text { with/without EU }\end{array}$} & \multicolumn{2}{|c|}{$\begin{array}{c}\text { Goods } \\
\text { Import/ } \\
\text { consumption }\end{array}$} & \multicolumn{3}{|c|}{$\begin{array}{l}\text { Tradable Services } \\
\text { Imports } \\
\text { with/without EU }\end{array}$} & \multicolumn{2}{|c|}{$\begin{array}{c}\text { Tradable Services } \\
\text { Import/ } \\
\text { consumption }\end{array}$} \\
\hline & Total & EU & non EU & $\begin{array}{l}\text { Total } \\
\text { With } \\
\text { EU }\end{array}$ & $\begin{array}{c}\text { Total } \\
\text { Without } \\
\text { EU }\end{array}$ & Total & EU & non EU & $\begin{array}{l}\text { Total } \\
\text { With } \\
\text { EU }\end{array}$ & $\begin{array}{l}\text { Total } \\
\text { Without } \\
\text { EU }\end{array}$ \\
\hline AUT & $131 \%$ & $152 \%$ & $87 \%$ & $60 \%$ & $48 \%$ & $119 \%$ & $132 \%$ & $96 \%$ & $13 \%$ & $11 \%$ \\
\hline BEL & $126 \%$ & $160 \%$ & $92 \%$ & $72 \%$ & $62 \%$ & $116 \%$ & $132 \%$ & $98 \%$ & $24 \%$ & $21 \%$ \\
\hline BGR & $118 \%$ & $156 \%$ & $88 \%$ & $55 \%$ & $47 \%$ & $122 \%$ & $134 \%$ & $99 \%$ & $11 \%$ & $9 \%$ \\
\hline CYP & $97 \%$ & $128 \%$ & $71 \%$ & $68 \%$ & $64 \%$ & $122 \%$ & $137 \%$ & $101 \%$ & $18 \%$ & $15 \%$ \\
\hline CZE & $136 \%$ & $163 \%$ & $93 \%$ & $61 \%$ & $48 \%$ & $116 \%$ & $127 \%$ & $94 \%$ & $14 \%$ & $12 \%$ \\
\hline DEU & $128 \%$ & $164 \%$ & $95 \%$ & $46 \%$ & $37 \%$ & $114 \%$ & $129 \%$ & $96 \%$ & $11 \%$ & $9 \%$ \\
\hline DNK & $124 \%$ & $153 \%$ & $87 \%$ & $59 \%$ & $49 \%$ & $112 \%$ & $132 \%$ & $97 \%$ & $19 \%$ & $17 \%$ \\
\hline ESP & $124 \%$ & $170 \%$ & $96 \%$ & $39 \%$ & $32 \%$ & $119 \%$ & $132 \%$ & $97 \%$ & $6 \%$ & $5 \%$ \\
\hline EST & $120 \%$ & $149 \%$ & $84 \%$ & $71 \%$ & $61 \%$ & $123 \%$ & $131 \%$ & $96 \%$ & $16 \%$ & $13 \%$ \\
\hline FIN & $126 \%$ & $162 \%$ & $92 \%$ & $44 \%$ & $35 \%$ & $110 \%$ & $127 \%$ & $93 \%$ & $13 \%$ & $12 \%$ \\
\hline FRA & $122 \%$ & $157 \%$ & $90 \%$ & $47 \%$ & $39 \%$ & $118 \%$ & $135 \%$ & $99 \%$ & $8 \%$ & $7 \%$ \\
\hline GBR & $111 \%$ & $151 \%$ & $87 \%$ & $47 \%$ & $42 \%$ & $119 \%$ & $137 \%$ & $101 \%$ & $8 \%$ & $7 \%$ \\
\hline GRC & $107 \%$ & $152 \%$ & $85 \%$ & $46 \%$ & $42 \%$ & $111 \%$ & $129 \%$ & $95 \%$ & $10 \%$ & $8 \%$ \\
\hline HRV & $122 \%$ & $149 \%$ & $86 \%$ & $54 \%$ & $45 \%$ & $116 \%$ & $131 \%$ & $96 \%$ & $12 \%$ & $10 \%$ \\
\hline HUN & $130 \%$ & $157 \%$ & $90 \%$ & $69 \%$ & $57 \%$ & $120 \%$ & $133 \%$ & $98 \%$ & $21 \%$ & $18 \%$ \\
\hline IRL & $120 \%$ & $159 \%$ & $87 \%$ & $79 \%$ & $71 \%$ & $106 \%$ & $131 \%$ & $97 \%$ & $52 \%$ & $49 \%$ \\
\hline ITA & $128 \%$ & $170 \%$ & $96 \%$ & $33 \%$ & $27 \%$ & $114 \%$ & $129 \%$ & $95 \%$ & $6 \%$ & $5 \%$ \\
\hline LTU & $117 \%$ & $160 \%$ & $91 \%$ & $68 \%$ & $61 \%$ & $113 \%$ & $134 \%$ & $100 \%$ & $19 \%$ & $17 \%$ \\
\hline LUX & $115 \%$ & $132 \%$ & $76 \%$ & $84 \%$ & $76 \%$ & $111 \%$ & $129 \%$ & $95 \%$ & $52 \%$ & $47 \%$ \\
\hline LVA & $118 \%$ & $147 \%$ & $84 \%$ & $64 \%$ & $55 \%$ & $123 \%$ & $134 \%$ & $99 \%$ & $11 \%$ & $9 \%$ \\
\hline MLT & $108 \%$ & $144 \%$ & $80 \%$ & $72 \%$ & $66 \%$ & $117 \%$ & $124 \%$ & $93 \%$ & $52 \%$ & $45 \%$ \\
\hline NLD & $125 \%$ & $170 \%$ & $97 \%$ & $67 \%$ & $57 \%$ & $118 \%$ & $142 \%$ & $104 \%$ & $19 \%$ & $16 \%$ \\
\hline POL & $132 \%$ & $165 \%$ & $94 \%$ & $43 \%$ & $33 \%$ & $126 \%$ & $144 \%$ & $105 \%$ & $10 \%$ & $8 \%$ \\
\hline PRT & $123 \%$ & $152 \%$ & $85 \%$ & $49 \%$ & $39 \%$ & $119 \%$ & $130 \%$ & $95 \%$ & $8 \%$ & $7 \%$ \\
\hline ROU & $123 \%$ & $154 \%$ & $88 \%$ & $39 \%$ & $32 \%$ & $127 \%$ & $141 \%$ & $104 \%$ & $9 \%$ & $7 \%$ \\
\hline SVK & $128 \%$ & $160 \%$ & $93 \%$ & $65 \%$ & $54 \%$ & $130 \%$ & $141 \%$ & $103 \%$ & $12 \%$ & $9 \%$ \\
\hline SVN & $129 \%$ & $158 \%$ & $90 \%$ & $68 \%$ & $56 \%$ & $120 \%$ & $134 \%$ & $98 \%$ & $14 \%$ & $12 \%$ \\
\hline SWE & $126 \%$ & $155 \%$ & $88 \%$ & $51 \%$ & $41 \%$ & $115 \%$ & $131 \%$ & $97 \%$ & $16 \%$ & $13 \%$ \\
\hline EU (mean) & $122 \%$ & $155 \%$ & $88 \%$ & $58 \%$ & $49 \%$ & $118 \%$ & $133 \%$ & $98 \%$ & $17 \%$ & $15 \%$ \\
\hline EU (median) & $123 \%$ & $157 \%$ & $88 \%$ & $59 \%$ & $48 \%$ & $118 \%$ & $132 \%$ & $97 \%$ & $13 \%$ & $12 \%$ \\
\hline
\end{tabular}

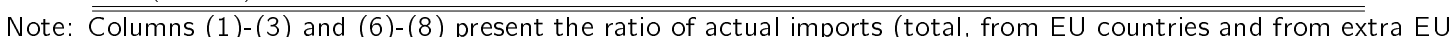
countries respectively) to imports in the counterfactual without the EU. A ratio larger than $100 \%$ indicates that the EU increases imports from the specific origin. Columns (4) and (9) report the actual openness ratio (import/consumption) for goods or tradable services and columns (5) and (10) the openness ratio in the counterfactual case without the EU. 